\title{
Upper Ocean Thermal Responses to Sea Spray Mediated Turbulent Fluxes during Typhoon Passage
}

\author{
Lianxin Zhang, ${ }^{1,2}$ Changlong Guan, ${ }^{3}$ Chunjian Sun, ${ }^{1}$ Siyu Gao, ${ }^{1}$ and Shaomei Yu ${ }^{4}$ \\ ${ }^{1}$ Key Laboratory of State Oceanic Administration for Marine Environmental Information Technology, \\ National Marine Data and Information Service, State Oceanic Administration, Tianjin 300171, China \\ ${ }^{2}$ College of Physical and Environmental Oceanography, Ocean University of China, Qingdao 266100, China \\ ${ }^{3}$ Physical Oceanography Laboratory, Ocean University of China, Qingdao 266100, China \\ ${ }^{4}$ Ocean Dynamical Laboratory, Third Institute of State Oceanic Administration, Xiamen 361005, China \\ Correspondence should be addressed to Lianxin Zhang; lxz_nmdis@163.com
}

Received 16 December 2014; Revised 30 January 2015; Accepted 18 February 2015

Academic Editor: Shaoqing Zhang

Copyright (C) 2015 Lianxin Zhang et al. This is an open access article distributed under the Creative Commons Attribution License, which permits unrestricted use, distribution, and reproduction in any medium, provided the original work is properly cited.

A one-dimensional turbulent model is used to investigate the effect of sea spray mediated turbulent fluxes on upper ocean temperature during the passage of typhoon Yagi over the Kuroshio Extension area in 2006. Both a macroscopical sea spray momentum flux algorithm and a microphysical heat and moisture flux algorithm are included in this turbulent model. Numerical results show that the model can well reproduce the upper ocean temperature, which is consistent with the data from the Kuroshio Extension Observatory. Besides, the sea surface temperature is decreased by about $0.5^{\circ} \mathrm{C}$ during the typhoon passage, which also agrees with the sea surface temperature dataset derived from Advanced Microwave Scanning Radiometer for the Earth Observing and Reynolds. Diagnostic analysis indicates that sea spray acts as an additional source of the air-sea turbulent fluxes and plays a key role in increasing the turbulent kinetic energy in the upper ocean, which enhances the temperature diffusion there. Therefore, sea spray is also an important factor in determining the upper mixed layer depth during the typhoon passage.

\section{Introduction}

When the wind speed reaches a certain level, surface wave breaking produces large numbers of sea spray droplets in the air-sea interface. Wave breaking and sea spray significantly affect the turbulent mixing [1,2] and turbulent fluxes [3], respectively, which play a key role in the upper ocean in the high wind speed condition ( $>25 \mathrm{~m} / \mathrm{s}$ ) [4] (e.g., typhoon). So the research method of sea spray has been concerned for several decades. Riehl (1954) [5] was the first to point that the sea spray evaporation provided a significant amount of heat. After twenty years, the sea spray problem caught high attention again [6-11]. Wu (1974) [10] observed sea spray's concentration in the wind-wave tank and computed the evaporation of sea spray. Bortkovskii (1973) [9] simply evaluated the energy and evaporation of the sea spray droplet and claimed that it is a primary source for enhancing the sea-air interfacial transfer in the high wind speeds. In addition, Ling and Kao (1976) [11] introduced sea spray evaporation into the equation of heat transfer and found that sea spray is also the important humidity source. In recent years, much research has focused on the effect of sea spray by developing theories [12-16]. Anthes (1982) [12] proposed that the evaporation of sea spray droplets would enhance the sensible heat transfer. Zhang and Lou [13] and Lou and Zhang [14] analyzed the physical processes of the individual sea spray droplet to get the expressions of spray heat flux and water vapor flux. Hasse (1992) [15] simply estimated the spray's impact by using three distinct arguments: the total surface area of sea spray droplet, an energy constraint, and the evaporation implied by the sea-salt aerosol. In recent years, much research has focused on the sea spray by the developing theories. Andreas [17-19] adapted Pruppacher and Klett's [20] cloud microphysical equations to study the thermal and moisture evolution of sea spray droplets. Fairall et al. [21] predigested Andreas's $[17,19]$ time scale and first incorporated a reasonable spray-based parameterization scheme into a simple model of the tropical cyclone boundary layer. So far, on 
the basis of the above studies, it is possible to calculate the sea spray induced heat flux using the actual observed data. At the same time, the sea spray heat algorithm presented by Fairall et al. [21] is basically valid for the high wind condition, since the sea spray generation function depends on wind speed and the whitecap areal fraction. In this study, the sea spray mediated heat flux is calculated following Fairall's sea spray algorithm in the typhoon passage. However, the feedback mechanism between the sea spray and the atmosphere is not considered in Fairall's sea spray algorithm. Therefore, the study will introduce the feedback mechanism into the airsea heat flux algorithm, which is feasible for us to calculate reasonable sea-air heat fluxes under the typhoon conditions.

Both theoretical researches [22] and field observations $[23,24]$ reveal that the drag coefficient leveled off or even decreased in the high wind speed. Powell et al. [23] hypothesized that sea spray could significantly influence the transfer of momentum for the wind speed above about $34 \mathrm{~m} / \mathrm{s}$. On the basis of field observations [23], Makin [25] suggested that a thin air boundary layer adjacent to the surface goes into a regime of limited saturation by suspended sea spray droplets, and the thin layer restrains the momentum transfer from the wind to the ocean. In the meantime, Makin [25] revised the wind speed logarithmic profile by the sea spray influence and derived the sea surface dynamic roughness length including the effect of sea spray at high winds. Based on the above research results, it is expected to investigate the momentum effect of sea spray during the typhoon passage through the spray induced sea surface dynamic roughness length.

Although the effect of the spray induced heat flux on air-sea interface under high winds was demonstrated by numerical simulations over a decade [26-30], the momentum effect of sea spray is hardly considered. In addition, little attention has been paid to both heat and momentum conjunct effects of sea spray on the upper ocean temperature in the period of typhoon by the numerical simulations. The goal of the present study is to investigate the impact of sea spray mediated turbulent fluxes on the upper ocean over the midlatitude oceans during a typhoon passage, using the General Ocean Turbulent Model (GOTM) that contains comprehensive turbulent mixing parameterizations. The effects of sea spray are presented from two kinds of physics processes. On the heat aspect, the impact of sea spray is considered in the form of modifying air-sea surface heat fluxes by microcosmic way, based on the sea spray microcosmic physical model from Fairall et al. [21]. On the momentum aspect, the effect of sea spray is introduced by the sea surface aerodynamic roughness length to investigate its impact on the air-sea momentum flux. As a pilot study, we present a case study of typhoon cyclone and explore the effects of sea spray in the numerical simulations.

The remainder of this study is organized as follows: model description and the spray turbulent flux algorithms are presented in Section 2. The experimental design of the numerical simulations is described in Section 3. Section 4 discusses numerical results and analyzes related mechanisms according to the model results, followed by the conclusions in Section 5.

\section{Model Description}

2.1. The GOTM Model. To clearly address the issue raised from the last section and avoid the complexity of a general circulation model, a one-dimensional ocean numerical model, namely, General Ocean Turbulence Model (denoted by GOTM) [31], which has a potential capability to simulate the vertical mixing processes near the upper ocean, is employed in this study. General Ocean Turbulent Model (GOTM) is a one-dimensional water column model (see http://www.gotm.net/), which solves the transport equations of heat, salt, and momentum. The governing equations of GOTM are formulated as

$$
\begin{gathered}
\frac{\partial \theta}{\partial t}-\frac{\partial}{\partial z}\left(v^{\prime} \frac{\partial \theta}{\partial z}\right)-\frac{\partial}{\partial z}\left(K_{h} \frac{\partial \theta}{\partial z}\right)=\frac{1}{\rho_{0} C_{p}} \frac{\partial I}{\partial z} \\
\frac{\partial S}{\partial t}-\frac{\partial}{\partial z}\left(v^{\prime \prime} \frac{\partial S}{\partial z}\right)-\frac{\partial}{\partial z}\left(K_{q} \frac{\partial S}{\partial z}\right)=0
\end{gathered}
$$

where $\theta$ and $S$ represent the mean potential temperature and salinity, respectively. $v^{\prime}$ and $v^{\prime \prime}$ denote the molecular diffusivities of heat and salt, respectively. $C_{p}$ is the heat capacity of seawater. $\rho_{0}$ is a constant reference density resulting from the Boussinesq approximation. The source term of temperature in the right-hand side of (1) is the vertical divergence of solar radiation $(I) . K_{q}$ and $K_{h}$ denote temperature and salinity diffusion coefficient. In the current version of GOTM, we set $K_{q}$ equal to $K_{h}$ for simplicity.

We will use the $k-\varepsilon$ second turbulence closure model to simulate turbulence parameters [32]. Within the framework, $K_{h}$ is equal to $c_{\mu}^{\prime} k^{1 / 2} l$. The nondimensional quantity $c_{\mu}^{\prime}$ is the function of nondimension stability parameter that describes the influence of stratification on turbulent mixing. $k$ is the turbulent kinetic energy and $l \propto k^{3 / 2} \varepsilon^{-1}$ is the integral length scale, computed here from the dissipation rate $\varepsilon$. The transport equation for the turbulent kinetic energy $k$ follows immediately from the contraction of the Reynolds-stress tensor. The equation of $k$ can be written as

$$
\frac{\partial k}{\partial t}=D_{k}+P+G-\varepsilon,
$$

where $P$ and $G$ are the turbulent production of $k$ by shear production and buoyancy generation, respectively, and $\varepsilon$ is the dissipation term of turbulent kinetic energy. $D_{k}$ represents vertical diffusion terms. In $k-\varepsilon$ model, the rate of dissipation is balanced according to

$$
\frac{\partial \varepsilon}{\partial t}=D_{\varepsilon}+\frac{\varepsilon}{k}\left(c_{\varepsilon 1} P+c_{\varepsilon 3} G-c_{\varepsilon 2} \varepsilon\right),
$$

where $D_{\varepsilon}$ represents the sum of the viscous and turbulent transport terms. The model constants $c_{\varepsilon 1}, c_{\varepsilon 2}$, and $c_{\varepsilon 3}$ are 1.44, 1.92 , and 1.44 , respectively.

\subsection{Air-Sea Flux Parameterizations}

2.2.1. COARE Model. To provide the external forcing for the GOTM, the surface fluxes in the air-sea interface are 
calculated from the mean model parameters using MoninObukhov Similarity Theory. The COARE version 2.6 bulk model turbulent fluxes of momentum $\tau$, latent heat $H_{L}$, and sensible heat $H_{S}$ are

$$
\begin{gathered}
\tau=\rho_{a} C_{d} U_{z_{l}}^{2}, \\
H_{S}=\rho_{a} c_{\mathrm{pa}} C_{h} U_{z_{l}}\left(\theta_{0}-\theta_{z_{l}}\right), \\
H_{L}=\rho_{a} L_{v} C_{k} U_{z_{l}}\left(q_{0}-q_{z_{l}}\right),
\end{gathered}
$$

where $\rho_{a}$ is the air density; $c_{\mathrm{pa}}$ is the specific heat of air at constant pressure; $L_{v}$ is the latent heat of vaporization of water; $\theta$ is the potential temperature and $q$ is the specific humidity. $U$ is the mean horizontal wind speed and the subscript $z_{l}$ denotes the lowest model level, while 0 refers to the water surface. $C_{d}, C_{h}$, and $C_{k}$ are the drag coefficient, the transfer coefficient for the sensible heat, and the latent heat, respectively:

$$
\begin{gathered}
C_{d n}=\frac{\kappa^{2}}{\ln ^{2}\left(z_{l} / z_{0}\right)}, \\
C_{h n}=\frac{\kappa^{2}}{\ln \left(z_{l} / z_{0}\right) \ln \left(z_{l} / z_{0 t}\right)}, \\
C_{k n}=\frac{\kappa^{2}}{\ln \left(z_{l} / z_{0}\right) \ln \left(z_{l} / z_{0 q}\right)} .
\end{gathered}
$$

Here $\kappa$ is the von Karman constant, while $z_{0}, z_{0 t}$, and $z_{0 q}$ are the roughness lengths for the velocity, temperature, and humidity, respectively. From laboratory studies it has proven convenient to characterize the surface and the flow regime by the roughness Reynolds number:

$$
R_{r}=\frac{u_{*} z_{0}}{v},
$$

where $v$ is the kinematic viscosity of air,

$$
\begin{aligned}
& z_{0 t}=\frac{R_{t} v}{u_{*}}, \\
& z_{0 q}=\frac{R_{q} v}{u_{*}},
\end{aligned}
$$

where $R_{t}$ and $R_{q}$, as the functions of $R_{r}$, are roughness Reynolds number for temperature and moisture.

Based on the COARE model, the next section introduces the parameterization of sea spray. The key feature of sea spray parameterization is that the heat and momentum effects of sea spray are recognized by the microcosmic and macroscopical aspects, respectively. On the macroscopical aspect, the sea surface aerodynamic roughness length with the effect of sea spray is used to investigate the impact of the sea spray on the drag coefficient and air-sea momentum flux. On the microcosmic aspect, the effects of heat fluxes induced by sea spray are introduced by the Fairall et al. [21] spray heat algorithm (henceforth FA94). Hence, the model includes the parameterizations for both the interfacial and the sea spray fluxes.
2.2.2. Sea Spray Affected Sea Surface Dynamic Roughness. In the original COARE version 2.6 bulk model, the Charnock relation is used to calculate the sea surface dynamic roughness length,

$$
z_{0}=\frac{\alpha_{c} u_{*}^{2}}{g},
$$

where $\alpha_{c}$ is Charnock constant and is set to 0.011 [33]. $g$ represents the acceleration due to gravity. Fairall et al. [33] pointed that the Charnock relation has been proven to work well for the low-moderate wind, and it is theoretically based and accurately for the interfacial turbulent fluxes for wind up to $10 \mathrm{~m} / \mathrm{s}$. When the wind speed reaches $11-13 \mathrm{~m} / \mathrm{s}$, the contribution of sea spray to the heat fluxes becomes significant. In other words, the Charnock relation does not contain sea spray droplets effect. Hence, the Charnock relation is still accurate for the interfacial turbulent fluxes when extrapolated to higher wind speeds.

For the high wind speed, the transfer coefficient for momentum flux decreases with the increasing of the wind, which is validated by the current field observations in the marine boundary layer $[23,24]$. Based on the field measures [23], Makin [25] introduces the effect of sea spray into the wind speed logarithmic profile and further gives the sea surface dynamic roughness length $z_{0}$ including the effect of sea spray for high wind speed:

$$
\begin{gathered}
z_{0}=\frac{c_{l}^{1-1 / \omega} \alpha_{c}^{1 / \omega} u_{*}^{2}}{g}, \\
\omega=\min \left(1, \frac{a_{\mathrm{cr}}}{\kappa u_{*}}\right), \\
c_{l}=\frac{g h_{l}}{u_{*}^{2}},
\end{gathered}
$$

where $\omega$ represents the correction parameterization indicating the effect of sea spray on the logarithm wind speed. The value of the terminal velocity $a_{\text {cr }}$ is estimated about $0.64 \mathrm{~m} / \mathrm{s}$ corresponding to a sea spray droplet radius of about $80 \mathrm{~m}$ [25]. $h_{l}$ is the height of the suspension layer in the regime of limiting saturation, which is proportional to and larger than the height of the breaking waves but smaller than the significant wave height $H$ by assuming that most of the spray at high wind speeds is produced by mechanical tearing by the wind from steep short waves. Hence, the height of the suspension layer in the regime of limiting saturation $h_{l}$ is about $1 / 10$ of the significant wave height $[25,34]$. In (10c), $c_{l}$ represents the nondimensionalized quantity of the height of the suspension layer in the regime of limiting saturation:

$$
c_{l}=\frac{1}{10} \frac{g H}{u_{*}^{2}} .
$$

It is found that the effects of sea spray are implied in the parameters $\omega$ and $c_{l}$ according to (10a), (10b), (10c), and (11).

For the low-to-moderate wind conditions $(<25 \mathrm{~m} / \mathrm{s}), z_{0}$ depends on both the wave states and wind speeds [35-39]. Donelan $[40,41]$ argued that laboratory experiments could 
not represent field conditions for the same wave ages, so observations of the laboratory experiments and the field conditions should be discussed separately. To simulate the real open ocean, $z_{0}$ is derived from the real open ocean condition and Donelan [40] can represent most results of the foregoing researcher for the moderate wind speed:

$$
\frac{z_{0} g}{u_{*}^{2}}=0.42\left(\frac{c_{p}}{u_{*}}\right)^{-1.03},
$$

where $c_{p}$ is peak wave phase velocity.

For the full wind speeds condition, the $z_{0}$ including the effect of sea spray is calculated by combining the $z_{0}$ for moderate wind (12) and for high wind ((10a), (10b), and (10c)), using the $3 / 2$ power law [42] and the relation between significant wave period and peak wave period:

$$
\frac{z_{0} g}{u_{*}^{2}}=0.0847^{(1-1 / \omega)} 0.42^{1 / \omega} \beta_{*}^{(3 / 2-253 / 100 \omega)}
$$

where $\beta_{*}$ is the wave age. When the impact of the sea spray droplets on the dynamics of the airflow at this regime is still small, $\omega$ should be equal to 1 , and fully wind conditional roughness length (13) degrades the low wind conditional roughness length (12). However, the impact of the sea spray on the sea surface roughness is large enough $(\omega<1)$, which leads to the decrease of the roughness length and the drag coefficient.

2.2.3. Spray Heat Flux Algorithm. The parameterization scheme for the sea spray heat fluxes used in this study follows FA94. This parameterization builds on earlier work on droplet microphysics and the associated timescales by Andreas [17, 19]. Thus, the spray droplet mediated sensible heat flux is proportional to the mass flux of all relevant spray droplets and the air-sea temperature difference:

$$
Q_{s}=S_{v} W(u) \gamma\left(u_{10}\right) \rho_{w} c_{p w}\left(T_{s}-T_{a}\right) .
$$

Here $\rho_{w}$ and $c_{p w}$ are the density and specific heat of liquid water. $W(u)$ is the whitecap areal fraction that is used to compute the sea spray droplet source number density spectrum. FA94 used the following form with the strong wind speed dependence:

$$
W(u)=3.8 \times 10^{-6} u^{3.4}
$$

from Monahan and Muircheartaigh [43]. $S_{v}$ is all the relevant whitecap normalized droplet volume flux:

$$
S_{v}=\int_{0}^{\infty} \frac{4 \pi}{3} r^{3} f_{n}(r) d r,
$$

where $f_{n}(r)$ is the source spectrum per unit area of whitecap. Evaluation of $S_{v}$ is straightforward from three different data sources [44-46], whose value is equal to $5.0 \times 10^{-6} \mathrm{~m} / \mathrm{s}$, which is independent of meteorological conditions.

Using the above approach, the spray droplet mediated latent heat flux is expressed as

$$
Q_{l}=S_{a} h W \gamma\left(u_{10}\right) \beta\left(T_{a}\right) \rho_{a} L_{e}\left[q_{s}\left(T_{a}\right)-q\right] \text {. }
$$

Here $q_{s}\left(T_{a}\right)$ is the saturation mixing ratio and spray droplets evaporate at their evaporating temperature $T_{\mathrm{ev}}$, which can be regarded as a wet-bulb temperature modified for the effects of salinity and curvature, and not at the air temperature. Thus $Q_{l}$ would be expected to be proportional to $q_{s}\left(T_{\mathrm{ev}}\right)-q$, rather than $q_{s}\left(T_{a}\right)-q$ as given. The term

$$
\beta\left(T_{a}\right)=\left[1+\frac{0.622 L_{e}^{2}}{R c_{\mathrm{pa}} T_{a}^{2}} q_{s}\left(T_{a}\right)\right]^{-1}
$$

where $R$ is the gas constant of dry air. The $10 \mathrm{~m}$ wind speed adjusted term

$$
\gamma\left(u_{10}\right)=1-0.087 \ln \left(\frac{10}{h}\right)
$$

Based on the Andreas [19] sea spray heat fluxes model, $S_{a}$ is set to $0.125 \mathrm{~s}^{-1}$ (given by FA94). The evaporation zone scale height $h$ is crudely defined as the height above the mean surface below which $67 \%$ of the total droplet evaporation takes place. $h$ is the evaporation zone scale height. Both measurements [47-49] and modeling studies [11, 50] confirm that the proper scaling height for the droplet evaporation zone is the mean wave height. For simplicity, FA94 considered mean wave height as the evaporation zone scale height.

FA94 argued that $Q_{l}$ and $Q_{s}$ represent upper limits and that the actual spray-dependent fluxes will be reduced by a factor due to the fact that mean profiles of $q$ and $T$ in the droplet zone do not remain logarithmic but are modified by the presence of the spray. Based on the numerical simulations $[16,51]$, the limited constant is about 0.5 (given by FA94). The equations for the spray sensible heat and latent heat flux are

$$
\begin{gathered}
Q_{s}=0.5 S_{v} W \gamma\left(u_{10}\right) \rho_{w} c_{p w}\left(T_{s}-T_{a}\right), \\
Q_{l}=0.5 S_{a} h W \gamma\left(u_{10}\right) \beta\left(T_{a}\right) \rho_{a} L_{e}\left[q_{s}\left(T_{a}\right)-q\right] .
\end{gathered}
$$

We note that $Q_{l}$ and $Q_{s}$ are the spray droplet mediated fluxes that would occur if the sea spray does not alter the normal logarithmic profile of mean $q$ and $T$ in the droplet evaporation zone.

2.2.4. Combined Turbulent Fluxes. The physical effects of sea spray between the air-sea interfaces are introduced from both the macroscopical and microcosmic ways. Concretely, the momentum (heat) effect of spray is introduced by the macroscopical (microcosmic) way.

Firstly, based on COARE 2.6 bulk model, the total airsea momentum $\tau_{\text {tot }}$ (including sea spray effect) is calculated by the sea surface dynamical roughness length with the sea spray effect at the full wind speeds (13); the interfacial airsea momentum $\tau_{\text {int }}$ (excluding sea spray effect) is computed by the Charnock relation (9). Hence the sea spray induced momentum flux is

$$
\tau_{s}=\tau_{\text {tot }}-\tau_{\text {int }}
$$


Secondly, the combined spray and interfacial fluxes constitute the boundary conditions. Andreas and DeCosmo [52] give the total sensible $\left(H_{S, T}\right)$ and latent $\left(H_{L, T}\right)$ heat fluxes as

$$
\begin{gathered}
H_{L, T}=H_{l}+\alpha Q_{l}, \\
H_{S, T}=H_{s}+\beta Q_{s}-(\alpha-\gamma) Q_{l} .
\end{gathered}
$$

Here, $H_{l}$ and $H_{s}$ are the interfacial latent and sensible heat fluxes that are computed by the COARE version 2.6 algorithms and described in Section 2.2.1. In (23a), $\alpha Q_{l}$ term models the latent heat flux (or moisture flux) coming out the top of the spray droplet evaporation layer that spray has contributed. However, FA94 pointed out that because the atmosphere must supply all the heat to evaporate the droplets, these droplets are a sink for sensible heat. Hence, to conserve energy, this $\alpha Q_{l}$ term in (23a) must appear with the opposite sign in the sensible heat equation (23b). The $\beta Q_{s}$ term in (23b) models the sensible heat that spray droplets give up in cooling from the ocean surface temperature $T_{s}$ to the temperature they have on returning to the sea surface. Thus, the $\gamma Q_{l}$ term in (23b) adds more sensible heat to the layer because of the increased air-sea temperature different that results from the spray's evaporative cooling of the layer.

Andreas [53] used the FA94 spray generation function to compute the spray heat fluxes and evaluate that the values of $\alpha, \beta$, and $\gamma$ are 3.3, 5.7, and 2.8 based on the HEXOS heat and moisture flux dataset. Hence coming by the above physics processes, the net sea spray contribution to the total sensible and latent heat fluxes can be estimated:

$$
\begin{gathered}
Q_{L, \mathrm{sp}}=\alpha Q_{l}, \\
Q_{S, \mathrm{sp}}=\beta Q_{s}-\alpha Q_{l}+\gamma Q_{l} .
\end{gathered}
$$

Hereafter, $Q_{L, s p}$ and $Q_{S, \text { sp }}$ are called sea spray induced sensible heat flux and latent heat flux, respectively.

\section{Experimental Design}

Two experiments are designed to investigate the influence of sea spray in the upper ocean during the passage of typhoon Yagi. According to the descriptions in Section 2, the air-sea turbulent fluxes without the effect of sea spray are computed in Test 1. On the basis of Test 1, Test 2 introduces the effect of sea spray into the air-sea turbulent fluxes. Based on the GOTM model and KEO observations, the 1D GOTM is configured to the position of the KEO station with a $400 \mathrm{~m}$ depth and 1200 vertical layers with intervals of $0.33 \mathrm{~m}$. To use the typhoon data, the simulation period is extended from September 17 to 29,2006 . Note that the ocean was initialized with the same temperature and salinity profiles from the KEO station in two cases. The numerical output such as air-sea momentum flux fields, heat fluxes fields, and sea temperature will be presented for sequent comparative analysis.

The Kuroshio Extension Observatory (KEO) is used in the GOTM model to simulate the typhoon Yagi, which is located at $32.4^{\circ} \mathrm{N}, 144.6^{\circ} \mathrm{E}$ and was first deployed in mid-June 2004. The measurements of KEO include $3 \mathrm{~m}$ air temperature, $3 \mathrm{~m}$ relative humidity, $3 \mathrm{~m}$ wind speed and direction, solar and

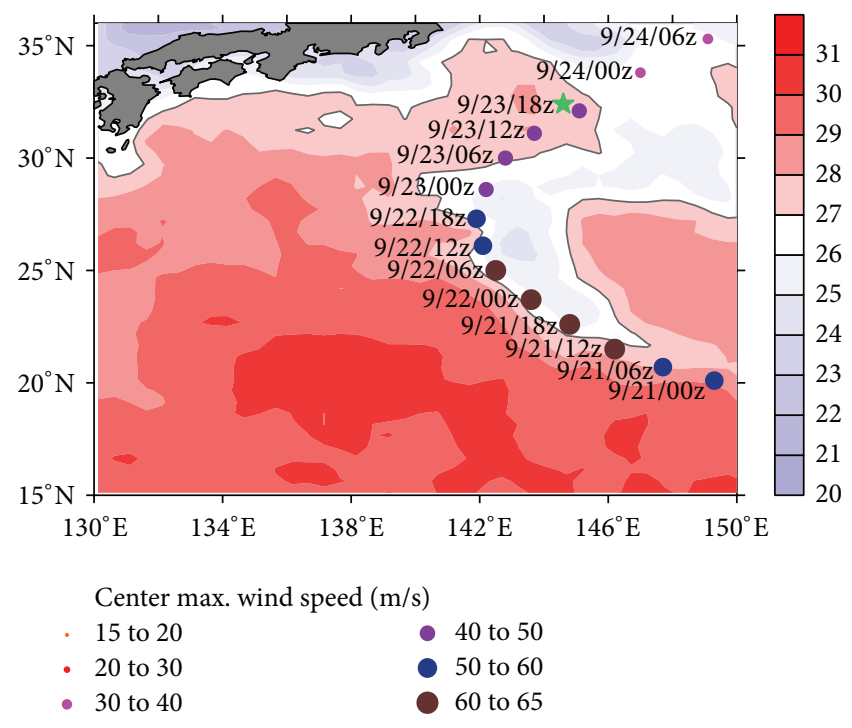

FIGURE 1: Daily averaged sea surface temperature (SST) (color fill, in ${ }^{\circ} \mathrm{C}$ ) derived from the Reynolds SST dataset on September 23. Green pentacle represents the location of the Kuroshio Extension Observatory (KEO) mooring. Color dots indicate the center location of Yagi on September 21-24 (every $6 \mathrm{~h}$ ). Thin black curves indicate the $27^{\circ} \mathrm{C}$ contour.

long-wave radiation, rain rate, sea temperature profile, and sea salinity profile. The temporal resolution of all variables is $10 \mathrm{~min}$, except for the radiations being 2 minutes. The observed layers of salinity and temperature are $1,10,15,50,75$, and $400 \mathrm{~m}$ and $1,10,15,25,50,75,100,150,200,300,400,450$, and $500 \mathrm{~m}$, respectively. The period of KEO variables used in the simulation is from September 17 to 29, 2006.

\section{Numerical Results}

Figure 1 shows the track of typhoon Yagi on September 21-24 (color dots) and the distribution of sea surface temperature on September 23 (shade) in the study area $\left(15-40^{\circ} \mathrm{N}, 130-\right.$ $150^{\circ} \mathrm{E}$ ). As shown in Figure 1, the typhoon Yagi upgraded to a supper typhoon on September 22. Subsequently, Yagi moved towards northeast and passed KEO station on September 23, where a broad area of low temperature can be seen distinctly around the right of Yagi [54]. On September 24, Yagi left the sea region, and the low temperature lasted until September 27 (not shown).

4.1. The Momentum Fluxes. The $10 \mathrm{~m}$ drag coefficient $C_{d}$ according to (6a), (6b), and (6c) is shown in Figure 2. When the effect of sea spray is considered, a significant dependence of $C_{d}$ on the wind speed and the wave age can be seen from the black dot lines in Figure 2. $C_{d}\left(z_{0}\right.$ derived from (13)) increases with the wind speed until the wind speed reaches $33 \mathrm{~m} / \mathrm{s}$ for different wave age. In the meantime, $C_{d}$ decreases with the increasing of the wave age when the wind speed remains constant. However, when the effect of sea spray is ignored, $C_{d}\left(z_{0}\right.$ derived from (9)) increases continually 


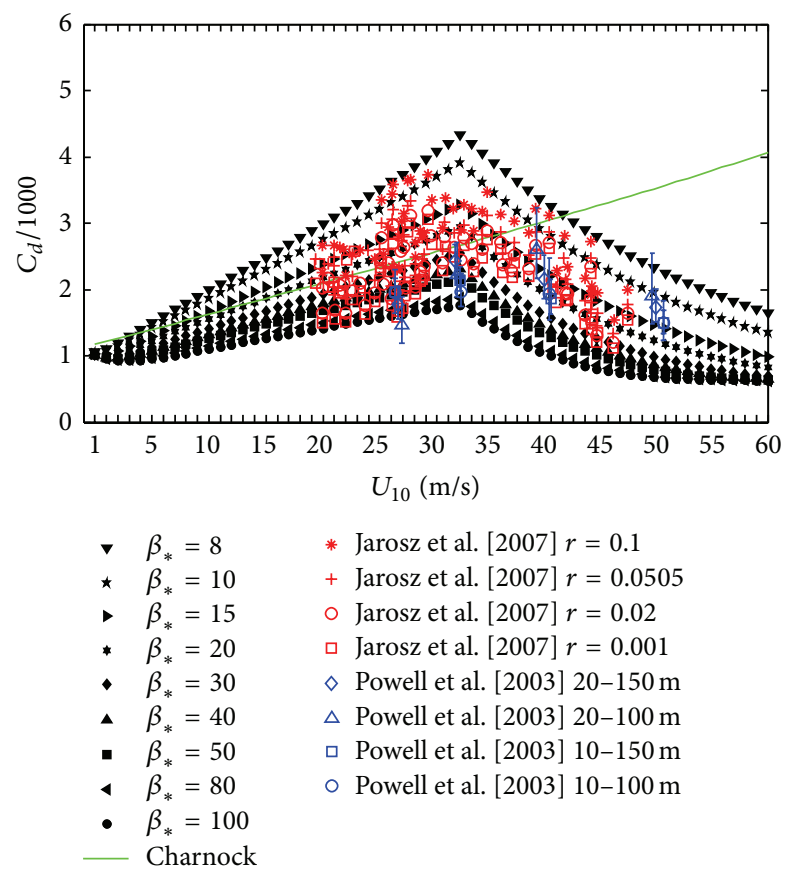

Figure 2: The change of drag coefficient with the $10 \mathrm{~m}$ wind speed on the different wave ages $(8,10,15,20,30,40,50,80$, and 100). The black dot lines represent the drag coefficient affected by the sea spray, which are calculated by (13). The drag coefficient without the effect of sea spray is indicated by the green line and calculated by the Charnock relation (9). The observations of Jarosz et al. (2007) based on different resistance coefficients $(0.1,0.0505,0.02$, and $0.001 \mathrm{~cm} / \mathrm{s}$ ) are plotted by the red dots. The blue dots represent the drag coefficient observed by Powell et al. (2003).

with wind speed and remains invariable with the wave age (green line). Further, the distribution of $C_{d}$ affected by the sea spray is in agreement with the counterpart obtained from the observations (Powell et al. [23] (blue markers) and Jarosz et al. [24] (red markers)). Therefore, the sea spray has positive impacts on $C_{d}$. It is important to figure out the physical process how sea spray affects $C_{d}$, which is described as follows: at very high wind speeds, a deep part of the marine atmospheric surface layer is filled with spray droplets, which forms the so-called suspension layer. In the suspension layer, the heaviest particles remain closer to the surface, so the spray droplets over the ocean form a very stable boundary layer close to the surface. As wind speeds exceed $33 \mathrm{~m} / \mathrm{s}$, the suspension layer in the regime of limiting saturation is formed, and the sea spray droplets influence the airflow dynamics, which can restrain the momentum transport from the wind to the sea surface [25].

Figure 3 depicts time series of surface momentum flux with and without sea spray at the fixed location of the KEO. As shown in Figure 3, prior to the passage of Yagi (September 20-22), sea spray has almost no effect on the momentum flux. When Yagi passed the KEO station, the momentum flux is significantly enhanced by the sea spray. The maximum total momentum fluxes (with the effect of sea spray) increase to

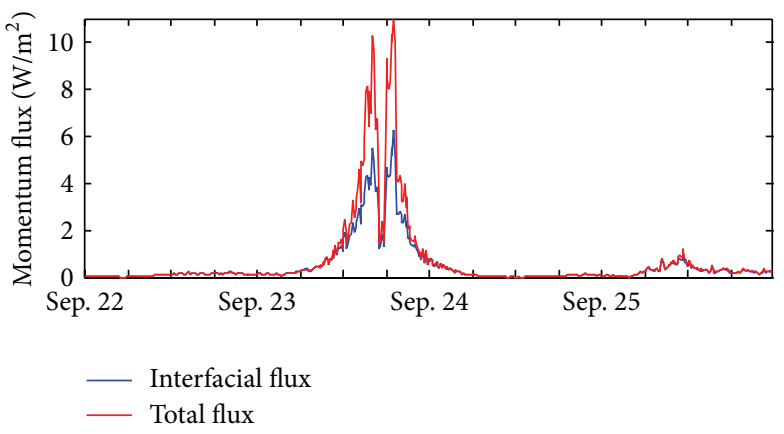

FIgURE 3: Time series of momentum flux at the KEO station where the simulated typhoon passed by at 18:00 September 23. Blue line and red line represent interfacial flux (without sea spray effect) and total flux (with sea spray effect), respectively.

10.29 N/m $\mathrm{m}^{2}$ and $11.38 \mathrm{~N} / \mathrm{m}^{2}$ at the peak winds on either side of the typhoon eye (Figure 3 red line). The increments of $4.79 \mathrm{~N} / \mathrm{m}^{2}$ and $5.13 \mathrm{~N} / \mathrm{m}^{2}$ are comparable with the interfacial momentum flux (without the effect of sea spray). When Yagi was far from the station gradually (September 24-29), the effect of sea spray on the momentum flux quickly decays.

4.2. The Heat Fluxes. Figure 4 shows time series of the total and interfacial heat flux, given by (22a)-(22b). As shown in Figure 4, the total heat flux (red line in Figure 4) is generally greater than the interfacial heat flux (blue line in Figure 4) during the typhoon Yagi period. The eye of typhoon Yagi passed the KEO station at 18:00 September 23 (Figure 1). The wind speed was nearly symmetric with the eye, and the maximum of the wind speed was $32.7 \mathrm{~m} / \mathrm{s}$ and $34 \mathrm{~m} / \mathrm{s}$, respectively (not shown). Hence, there are double peaks of the heat flux symmetric with the typhoon eye (Figure 4). When the typhoon Yagi passed the KEO station on September 23 , the maximal interfacial latent heat flux is $533.8 \mathrm{~W} / \mathrm{m}^{2}$ (blue line in Figure 4(b)), and the maximal total latent heat flux is $738.2 \mathrm{~W} / \mathrm{m}^{2}$ (red line in Figure $4(\mathrm{~b})$ ). The latent heat flux is maximally increased by $204.4 \mathrm{~W} / \mathrm{m}^{2}$ (spray mediated latent heat flux $Q_{L, s p}$ ) at the peak winds on the right side of the typhoon eyes. In the meantime, the total maximum sensible flux is $298.2 \mathrm{~W} / \mathrm{m}^{2}$ (red line in Figure 4(a)), which is an increment of $106.5 \mathrm{~W} / \mathrm{m}^{2}$ compared with the interfacial maximum sensible heat flux (blue line in Figure 4(a)).

4.3. Sea Temperature. In this section, the daily SST simulated by the GOTM during the passages of typhoon Yagi is compared with the AMSR-E and Reynolds satellite data. Figure 5 shows the variation of daily SST simulated by Test 1 (blue curves) and Test 2 (red curves) during the passage of Yagi. For comparison, the AMSR-E (black pentacle line) and Reynolds (black star line) SST are also plotted. Results of two tests are consistent with the observed SST before the typhoon Yagi passed the KEO station (on September 18-19). After Yagi left the KEO station (i.e., September 23-26.), the significant decreasing trend of the SST can be seen from variation of 


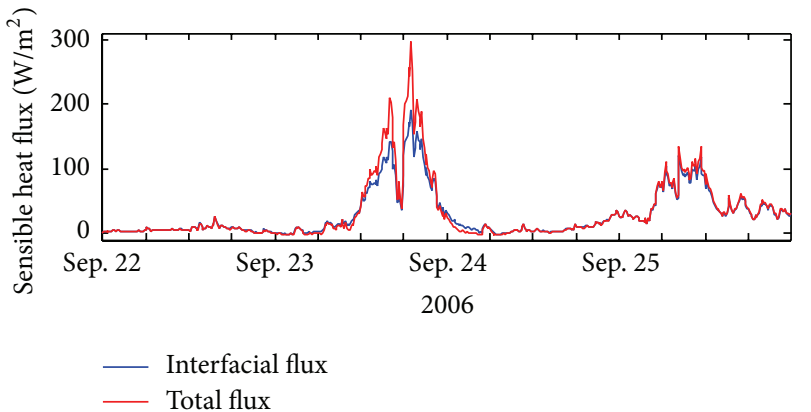

(a)

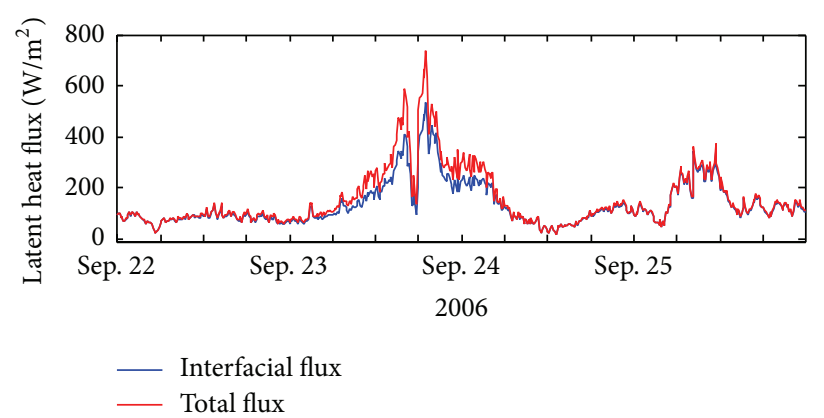

(b)

FIgURE 4: Time series of (a) sensible heat flux and (b) latent heat flux at the KEO station where the simulated typhoon passed by at 18:00 September 23. Blue line and red line represent interfacial heat flux and total heat flux, respectively.

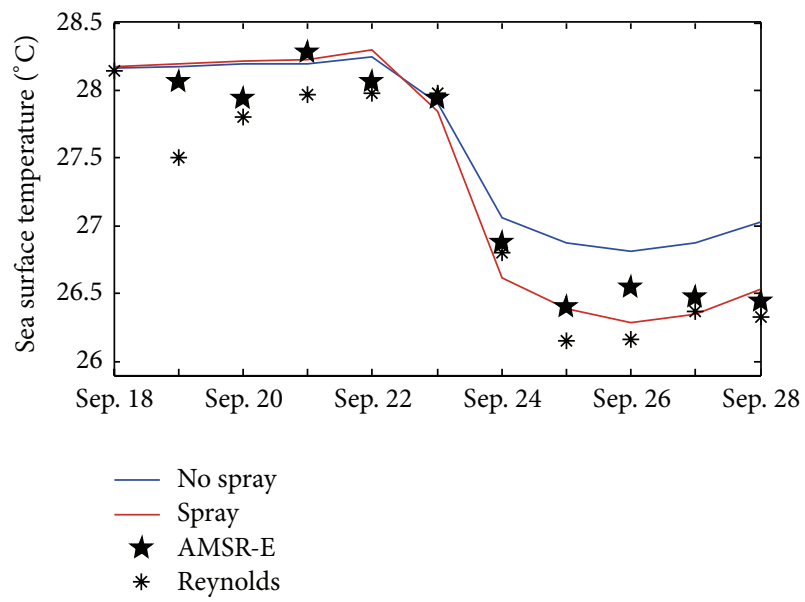

FIGURE 5: Variation of daily averaged SST during the passage of typhoon Yagi. Red and blue curves represent results of test including spray effect (Test 1 ) and excluding spray effect (Test 2), respectively. Black pentacle line and black star line represent AMSR-E and Reynolds SST, respectively.

daily averaged SST. On September 25, the SST of AMSR-E and Reynolds reaches $26.4^{\circ} \mathrm{C}$ and $26.15^{\circ} \mathrm{C}$, respectively. Compared with SST simulated by Test $1\left(26.88^{\circ} \mathrm{C}\right)$, the SST of Test 2 decreases to $26.39^{\circ} \mathrm{C}$, which is closer to the observations from the AMSR-E and Reynolds. The difference in the two experiments indicates that the sufficient cooling of the SST can be reproduced if the effect of sea spray is considered.

Figure 6 shows time series of the mixed layer depth (MLD) for the two tests with and without the sea spray effect, where the MLD is derived from the turbulent kinetic energy threshold. When the sea spray fluxes algorithms are included in GOTM, the maximal MLD is $52.49 \mathrm{~m}$ for the no spray case (Test 1 ) and $68.87 \mathrm{~m}$ for the with spray case (Test 2) on September 24. The MLD difference in two tests illuminates that sea spray can deepen the MLD during the typhoon passage in the GOTM simulation.

Figure 7 shows the influence of sea spray in the upper $100 \mathrm{~m}$ profiles of temperature at 12:00 September 21-26

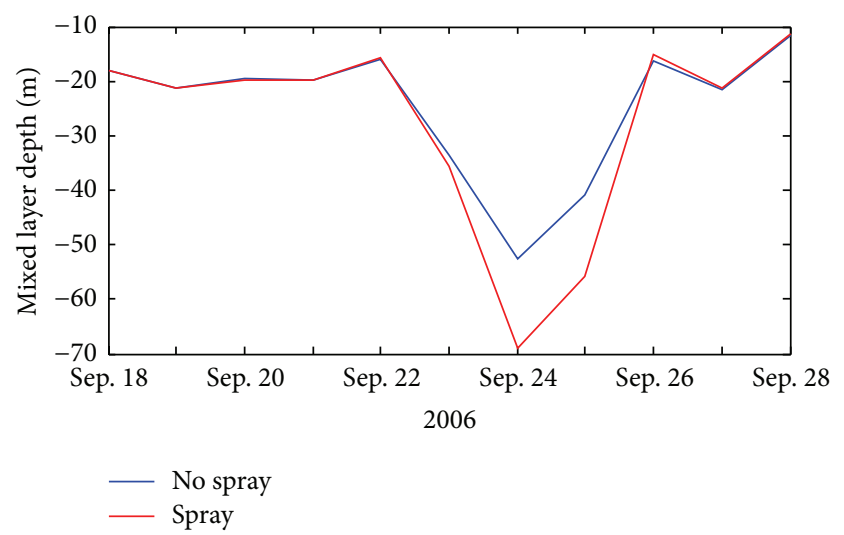

FIgURE 6: Time series (daily) of the mixed layer depth from simulations with (Test 2) and without (Test 1) sea spray effect at the fixed station. The red (blue) line is the mixed layer depth with (without) sea spray effect.

((a)-(f)). Results show that Test 2 can capture the trend of temperature reduction in the upper ocean layer after Yagi left the KEO station. The upper layer temperature profiles of Test 2 (red lines) are more similar to the KEO observations (gray asterisks) than those of Test 1 (blue lines) during the Typhoon passage. The simulated temperature profile of Test 2 especially cooled significantly after the typhoon's passage (September 24-26). The temperature simulated by Test 2 is cooler by $0.5^{\circ} \mathrm{C}$ than that simulated by Test 1 . Hence, the effect of sea spray can yield additional cooling during the typhoon Yagi simulation.

\section{Discussion}

5.1. The Effect of Sea Spray on Momentum Fluxes. When the sea spray droplets are ejected into the air, they are accelerated by the air drag. At one time, the sea spray droplets extract the momentum from the airflow. When sea spray droplets crash back into the sea surface, they transfer their momentum to the ocean. Momentum transfer is carried out from the air to the ocean by the sea sprays. So the effect of sea spray on 


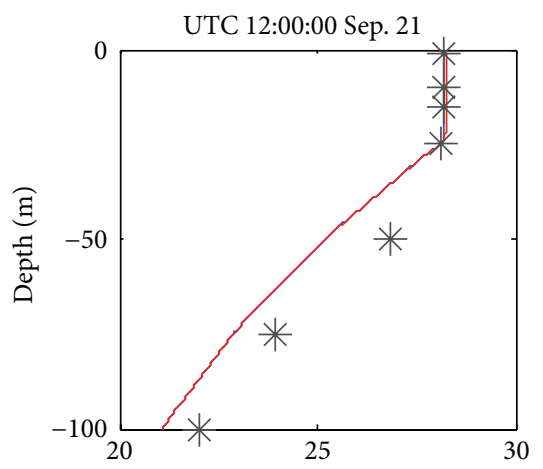

(a)

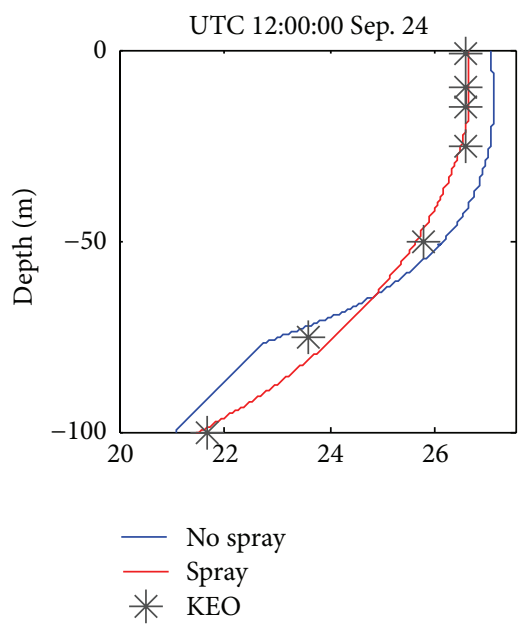

(d)

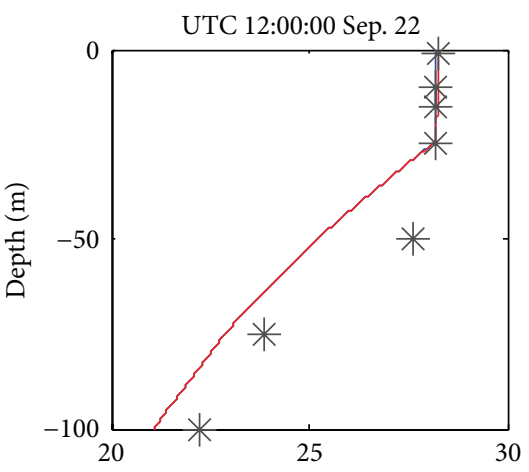

(b)

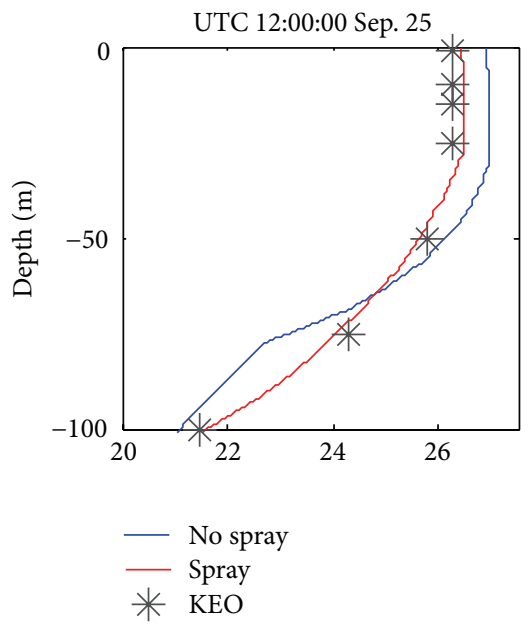

(e)

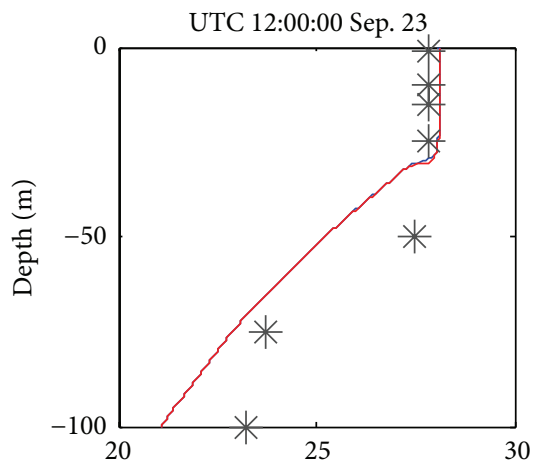

(c)

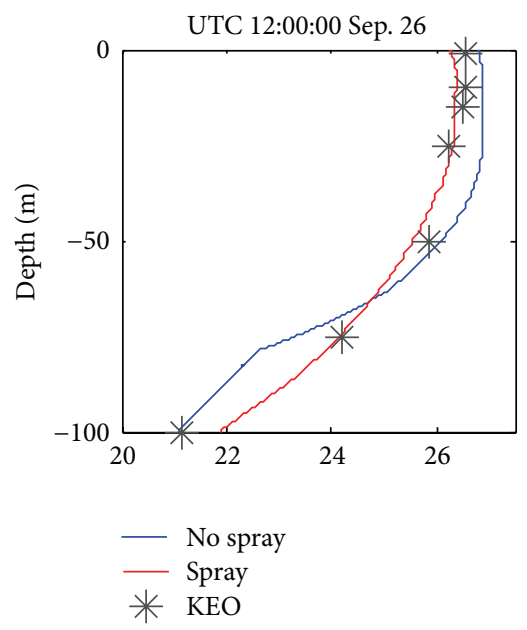

(f)

Figure 7: Upper $100 \mathrm{~m}$ temperature profiles simulated by Test 1 (no spray, blue curves) and Test 2 (spray, red curves) at ((a)-(f)) 12:00 September 21-26, 2006. Gray asterisks indicate the KEO observed temperature.

momentum exchange should be evaluated in the real typhoon period. To clearly analyze the distribution characteristic of the momentum fluxes, the trends of momentum fluxes as a function of wind speed are shown in Figure 8. For the wind speed less than $20 \mathrm{~m} / \mathrm{s}$, the spray mediated momentum flux (red dot line in Figure 8(a)) is about two orders of magnitude less than the interfacial momentum flux (blue dot line in Figure 8(a)), which is in agreement with the depiction in Andreas and Emanuel [55]. The growth rate of spray momentum flux is far less than that of interfacial momentum flux, whereas, for wind speeds over $20 \mathrm{~m} / \mathrm{s}$, the growth rate of spray momentum flux with wind increasing is much greater than the rate of interfacial momentum flux. When wind speed reaches $31 \mathrm{~m} / \mathrm{s}$, both the spray momentum flux (red dot line in Figure 8(b)) and the interfacial momentum flux (blue dot line in Figure 8(b)) are almost equal. This conclusion can be corroborated by the result of previous studies about spray momentum flux. For example, Andreas and Emanuel [55] evaluated the spray momentum flux using the spray generation functions of Andreas [19]. If the spray momentum grows using prevailing growth rates, the interfacial momentum and the spray momentum are equal at about $u_{*}=2 \mathrm{~m} / \mathrm{s}$ (Figure 8 in Andreas and Emanuel [55]); this $u_{*}$ corresponds to a surface-level wind speed of about $32 \mathrm{~m} / \mathrm{s}$. Hence it indicated that result is considerably reasonable in this study. It is worth noting that, for the wind speed greater than $33 \mathrm{~m} / \mathrm{s}$, the growth of spray momentum flux does not continuously increase as the interfacial momentum flux does. The growth rate of the total momentum flux decreases due to the influence of the sea spray. Because of wind speeds exceeding $33 \mathrm{~m} / \mathrm{s}$, regime of limiting saturation suspension layer is formed by the spray in air-sea interface surface layer, which can influence the airflow dynamics. Hence, with the effect of sea spray, the growth rate of total momentum flux reduces in the high wind condition.

5.2. The Effect of Sea Spray on Heat Fluxes. Based on the results, the sea spray plays an important role in the air-sea transfer of sensible heat and latent heat. To clearly analyze the characteristic of the sea spray fluxes, the trends of sea spray mediated sensible heat flux $Q_{S, \text { sp }}$ and latent heat flux $Q_{L, \mathrm{sp}}$ as a function of wind speed are shown in Figure 9. From 


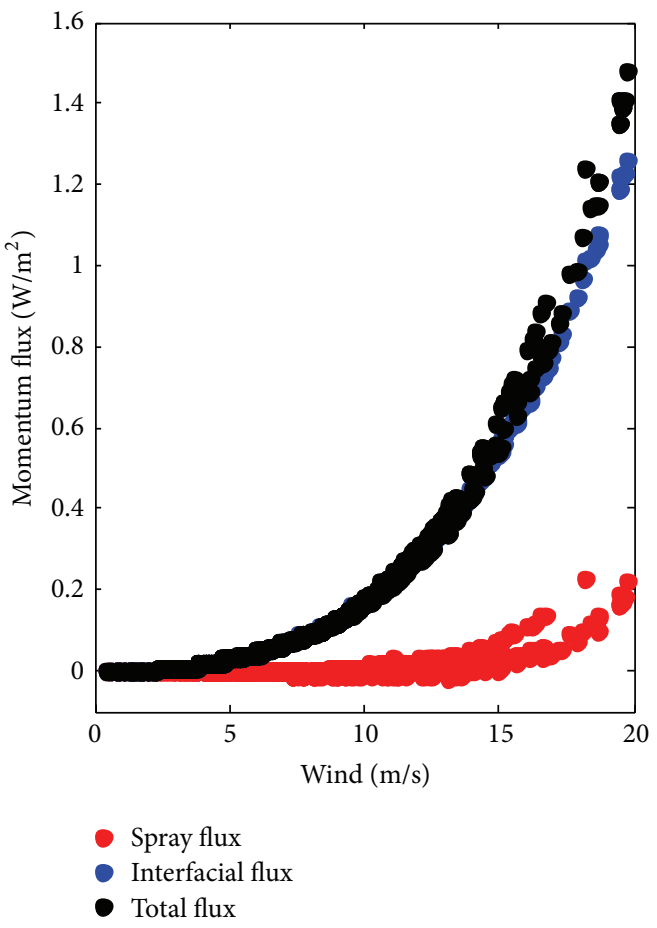

(a)

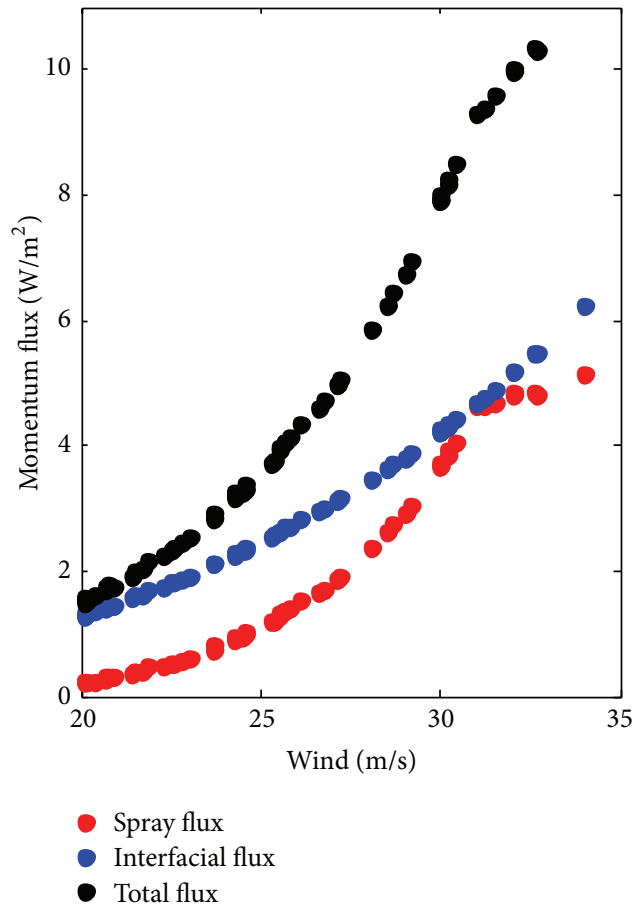

(b)

Figure 8: Magnitude of the momentum flux as a function of wind speed for the wind speeds from (a) 0 to $20 \mathrm{~m} / \mathrm{s}$; (b) 20 to $35 \mathrm{~m} / \mathrm{s}$. (Black dot line, blue dot line, and red dot line represent total momentum flux, interfacial momentum flux, and sea spray momentum flux, resp.).

Figure 9, one can see that the effect of sea spray on the airsea heat fluxes is restricted by the sea surface wind speed condition. When the wind speed is greater than $10 \mathrm{~m} / \mathrm{s}$, sea spray begins to modulate the heat and moisture transfer in the air-sea interface. For wind speed greater than $20 \mathrm{~m} / \mathrm{s}$, sea spray significantly affects the air-sea sensible and latent heat flux. In addition, sea spray enhances latent heat transfer from the sea to the air for all the wind speed condition. For the sensible heat flux, sea spray sometimes enhances sensible transfer from the sea to the air and sometimes enhances sensible transfer from the air to the sea, which indicates there are complicated physical processes between the spray droplet evaporation layer and the air-sea interface in the heat exchange. In other words, the sign (positive or negative sign) of the sea spray induced sensible heat flux $Q_{S, \text { sp }}$ is decided by the sea spray giving up sensible heat term $\left(\beta Q_{s}\right)$, the sea spray's evaporation absorbing sensible heat term $\left(-\alpha Q_{l}\right)$, and adding more sensible heat term $\left(\gamma Q_{l}\right)$ due to the sea spray's feedback mechanism, according to (23b). For example, sea spray's evaporation absorbing sensible heat term $-\alpha Q_{l}$ is increased to $-204.4 \mathrm{~W} / \mathrm{m}^{2}$, which reduces the turbulent enthalpy flux from the ocean to the air. The maximum of $\beta Q_{s}$ is $137.4 \mathrm{~W} / \mathrm{m}^{2}$ (blue line in Figure $10(\mathrm{~b})$ ), and $\gamma Q_{l}$ is 173.4 W/ $/ \mathrm{m}^{2}$ (orange line in Figure 10(a)). Hence, combining the above physics processes, the maximal spray mediated sensible heat flux $Q_{S, \text { sp }}$ increases to $106.5 \mathrm{~W} / \mathrm{m}^{2}$ (red line in Figure 10(b)).
5.3. Diagnostic Analysis of Sea Temperature. Sea spray acts as an additional source of the air-sea turbulent fluxes and can improve the magnitudes of the turbulent kinetic energy $k$ and temperature diffusion coefficient $K_{h}$ in the upper ocean, which affect the upper layer sea temperature during the typhoon passage. So $k$ equation (3) of the model is diagnosed to investigate the effect of sea spray. Figures 11 and 12 show the shear production term $P$ and the dissipation term $\varepsilon$ of the total tke in the upper ocean $(<100 \mathrm{~m})$, respectively. Terms of the vertical diffusion term $D_{k}$ and buoyancy generation term $G$ are not shown because their magnitude are much smaller. The shear production term $P$ (Figure 11) is balanced by the dissipation term $\varepsilon$ (Figure 12). The most significant increment in Figure 11 is due to the high dissipation because strong shear happens there induced by strong turbulent fluxes of sea spray near the sea surface, when the typhoon Yagi passes the KEO station (on September 23). On September 24-26, the increasing trend of $P$ spreads downward to $100 \mathrm{~m}$. In a word, sea spray mediated turbulent fluxes primarily enhance the shear production term $P$ of the total tke in the upper ocean during the typhoon Yagi passage. Hence, when the effect of sea spray is considered, the total tke is enhanced greatly in the upper ocean (see Figure 13). On the sea surface, the total tke increases from $0.0044 \mathrm{~m}^{2} / \mathrm{s}^{2}$ without the sea spray effect (blue line in Figure 13) to $0.0077 \mathrm{~m}^{2} / \mathrm{s}^{2}$ with the sea spray effect (red line in Figure 13). When the typhoon left the KEO station for 2-3 days (i.e., September 24-26), the increasing trend of 


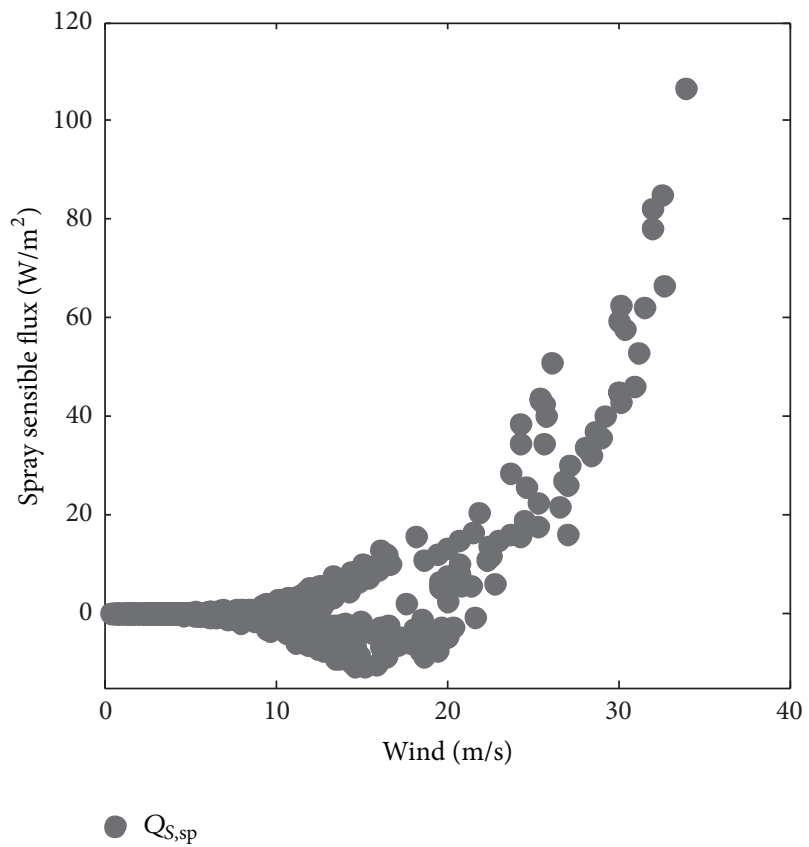

(a)

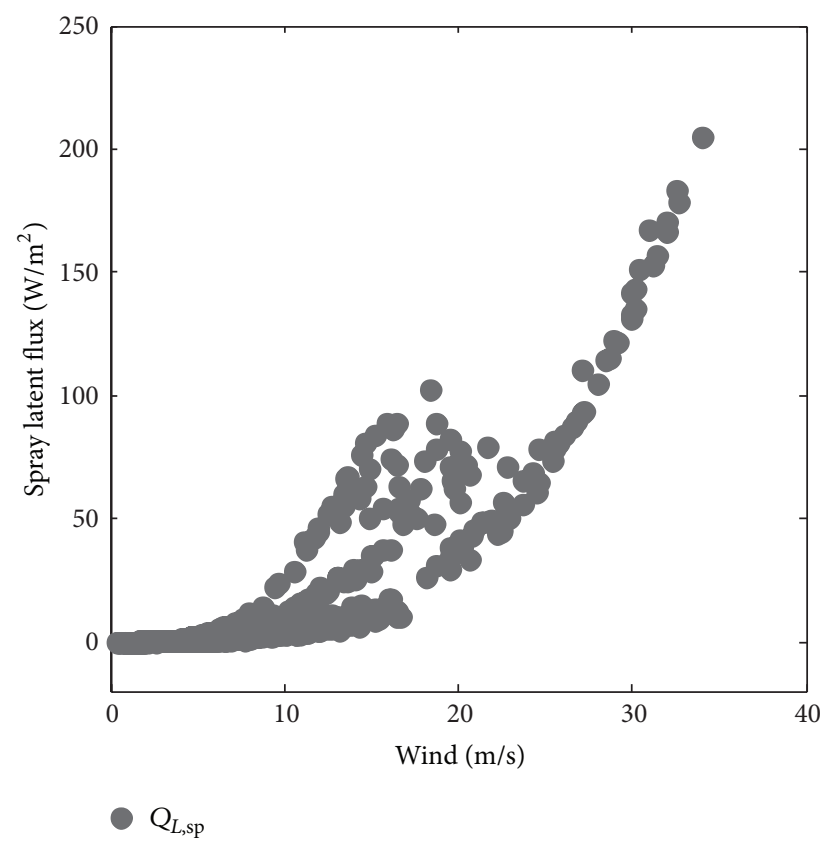

(b)

Figure 9: Sea spray induced heat fluxes. (a) Spray sensible flux $Q_{S, s p}$. (b) Spray latent flux $Q_{L, s p}$ as a function of wind speed.

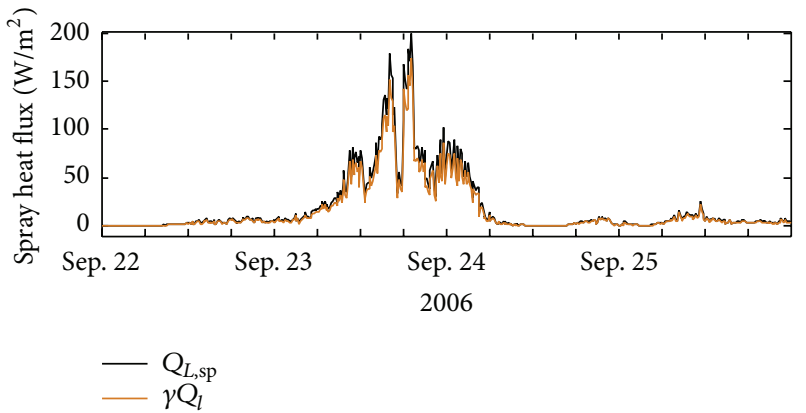

(a)

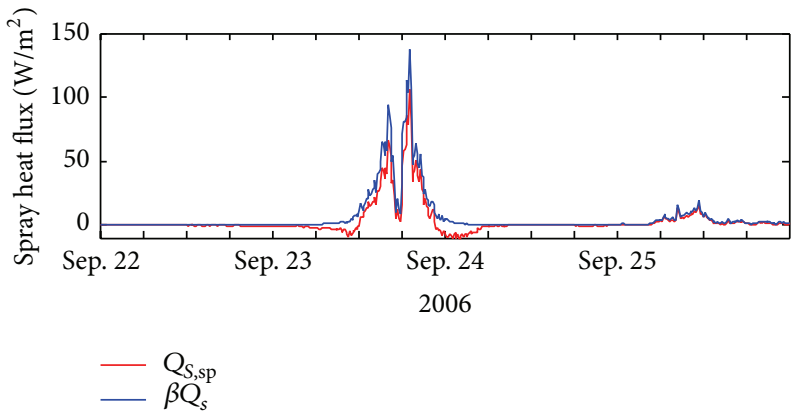

(b)

FIGURE 10: Time series of spray heat flux at the KEO station. Black line and orange line represent the sea spray mediated latent $Q_{L, s p}$ and added heat flux of spray increased air-sea temperature different $r Q_{l}$ in Figure 10(a), respectively. Red line and blue line indicate sea spray mediated sensible heat $Q_{S, \text { sp }}$ flux and spray sensible heat $\beta Q_{s}$ in Figure 10(b), respectively.

the total tke spreads downward to $100 \mathrm{~m}$. The enhanced turbulent kinetic energy derived from the sea spray's turbulent fluxes mixes the water column and makes it more homogeneous.

$K_{h}$ from the surface to about $70 \mathrm{~m}$ depth has an increment owing to the enhancement of the turbulent kinetic energy by sea spray induced turbulent fluxes on September 23 (Figure 14(a)). $K_{h}$ of Test 2 (red line in Figure 14(b)) is increased by approximately three times at the sea surface compared to that of Test 1 (blue line in Figure 14(b)). After the typhoon Yagi left the KEO station (September 24-26), the enhancing $K_{h}$ spreads downwards (red line in Figures $14(\mathrm{c})-14(\mathrm{e}))$ cooling the temperature of the upper ocean and increasing the depth of the ocean mixed layer. Combining the turbulent kinetic energy $\varepsilon$ and the temperature diffusion coefficient $K_{h}$, the effect of sea spray significantly cools the temperature of the upper ocean. This cooling is maintained for 2-3 days, which is consistent with the observations in situ.

\section{Conclusion}

In the high wind speed condition (e.g., typhoon), breaking waves in the air-sea interface can produce large amount of sea spray droplets, which significantly affect the dynamic and the thermodynamic processes between the ocean and the atmosphere. To investigate the effects of sea spray on the sea 


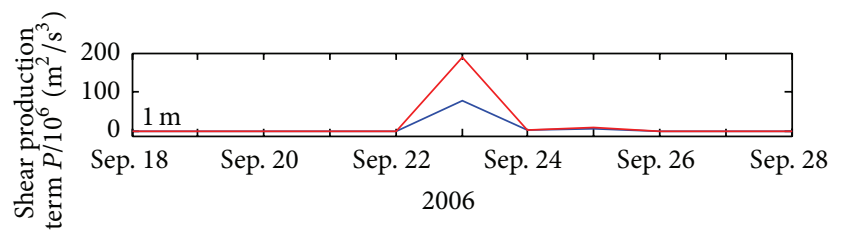

(a)

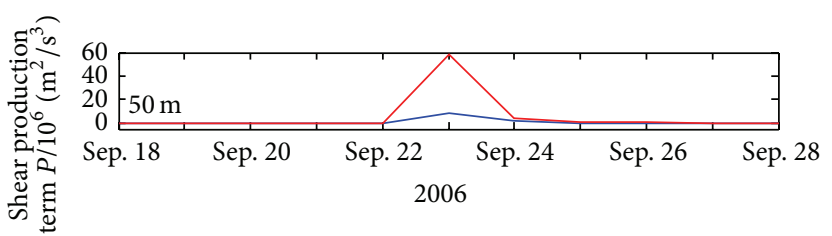

(c)

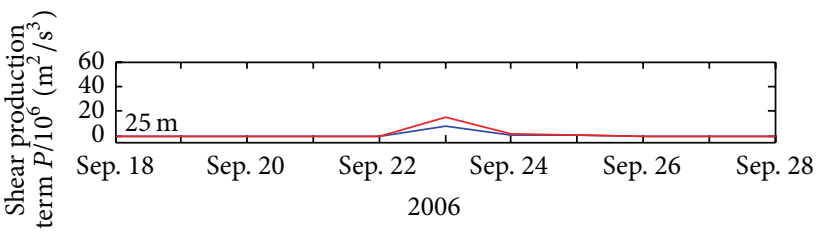

(b)

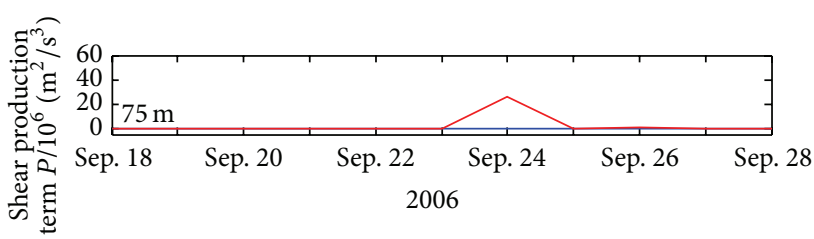

(d)

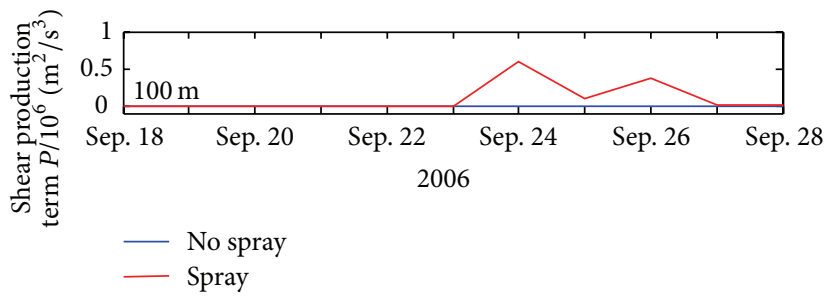

(e)

Figure 11: Time series (daily) of the shear production term $P$ from simulations with (red curves) and without sea spray (blue curves) at the KEO station in (a) $1 \mathrm{~m}$, (b) $25 \mathrm{~m}$, (c) $50 \mathrm{~m}$, (d) $75 \mathrm{~m}$, and (e) $100 \mathrm{~m}$ depth.

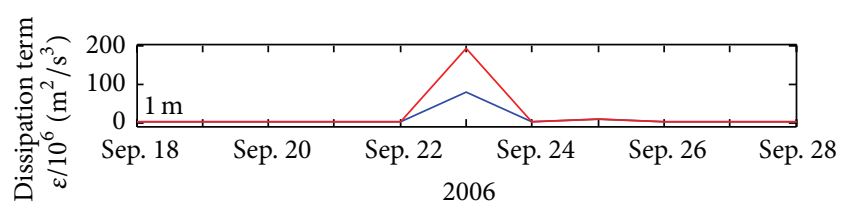

(a)

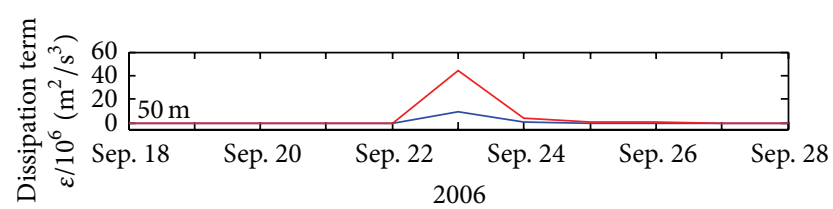

(c)

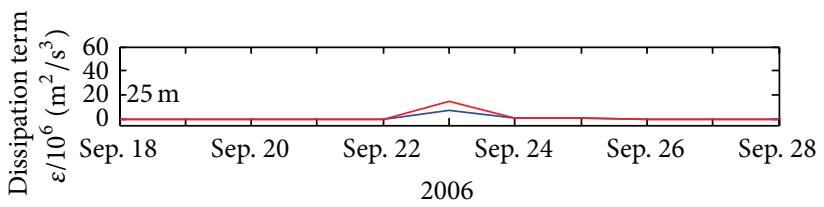

(b)

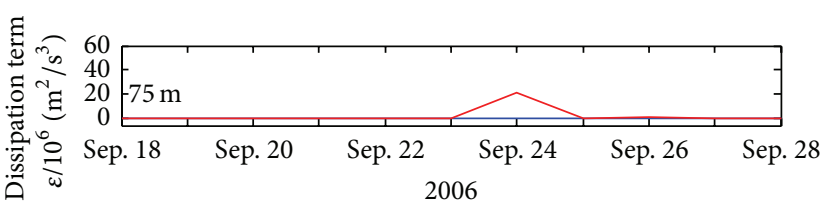

(d)

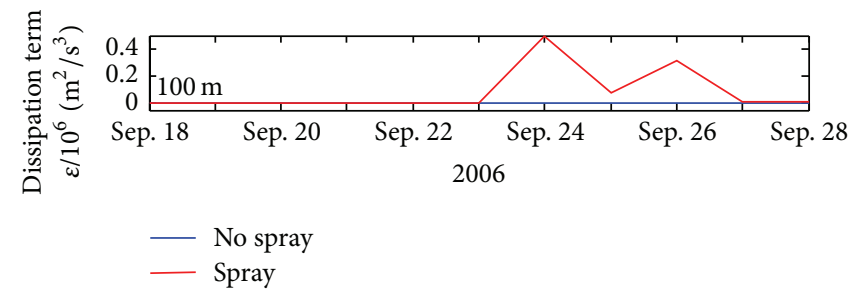

(e)

FIGURE 12: The same as Figure 11, but for the dissipation term $\varepsilon$. 


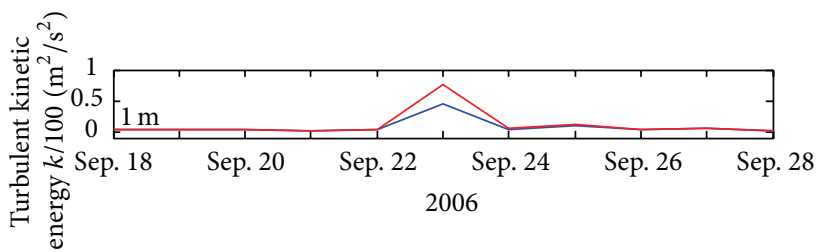

(a)

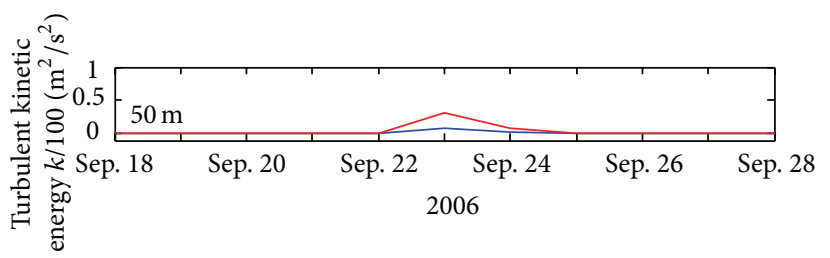

(c)

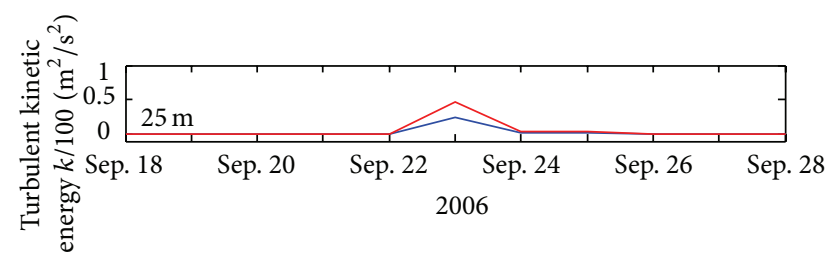

(b)

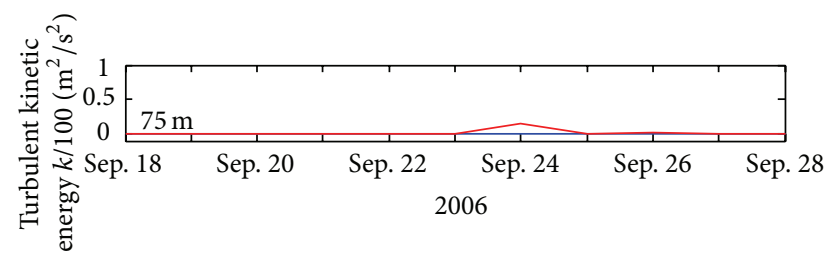

(d)

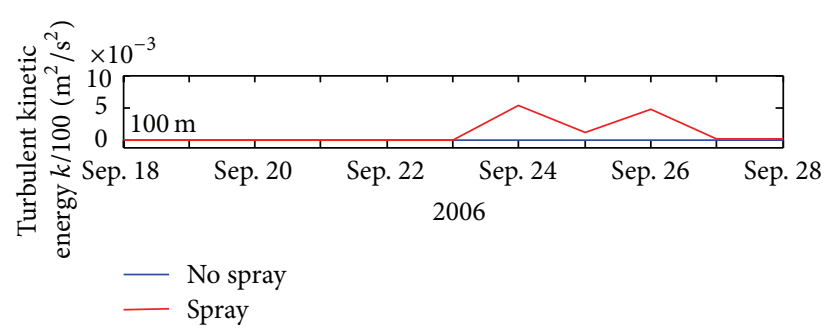

(e)

FIGURE 13: The same as Figure 11, but for the total turbulent kinetic energy $k$.

surface boundary layer during typhoon passage, the General Ocean Turbulent Model is used to simulate the characteristics of the upper layer sea temperature and the turbulent mixing on real typhoon Yagi in 2006. Different from early studies, the effect of sea spray on the air-sea turbulent fluxes is parameterized by the following two comprehensive ways. On the momentum aspect, the macroscopical effect of sea spray is introduced into the parameterization of sea surface roughness for the full wind speed conditions. On the heat and moisture aspect, the effect of sea spray is simulated by the FA94 microcosmic sea spray flux algorithm. In addition, the study introduces the feedback mechanism of sea spray into the air-sea heat flux algorithm. The effect of sea spray is completely introduced into the COARE model and GOTM. Numerical results show that the air-sea turbulent fluxes are significantly enhanced by introducing the impact of sea spray in the GOTM during the typhoon Yagi passage. Sea spray mediated turbulent fluxes nonlinearly increase with the wind speed increasing. When wind speed exceeds $20 \mathrm{~m} / \mathrm{s}$, sea spray begins to significantly affect the air-sea turbulent fluxes, whereas, for wind speeds over $30 \mathrm{~m} / \mathrm{s}$, the sea spray mediated momentum flux is comparable with the interfacial momentum flux. Combining the complex feedback processes of the sea spray, the maximal net contribution of the sea spray to the total latent heat and sensible heat flux is 204.40 and $106.46 \mathrm{~W} / \mathrm{m}^{2}$, respectively.
In addition, the effect of sea spray on the upper ocean is analyzed by the diagnostic equation of turbulent kinetic energy and temperature diffusion coefficient. Diagnostic results show that the turbulent kinetic energy and the temperature diffusion coefficient have an increment due to considering the effect of sea spray from the surface to about $50 \mathrm{~m}$ depth. With the typhoon leaving the KEO station, this increasing trend spreads downward to $100 \mathrm{~m}$. The enhanced turbulent kinetic energy derived from the sea spray's turbulent fluxes intensively mixes the water column and cools the temperature of the upper ocean for 2-3 days. Hence, with the effect of sea spray included, the ocean upper temperature is decreased by about $0.5^{\circ} \mathrm{C}$, which is in agreement with the observations of KEO, AMSR-E, and Reynolds during the typhoon passage.

In conclusion, sea spray acts as an additional source of the air-sea turbulent fluxes and can improve the magnitudes of the turbulent kinetic energy and temperature diffusion coefficient in the upper ocean. Therefore, we suspect that sea spray is an indispensable factor in modulating the mixed layer temperature during the typhoon passage. However, there are still some discrepancies between the observation and the simulation due to the limitation of GOTM, which ignores the horizontal advection and other associated physical processes. Further, three-dimensional general ocean model or air-sea 


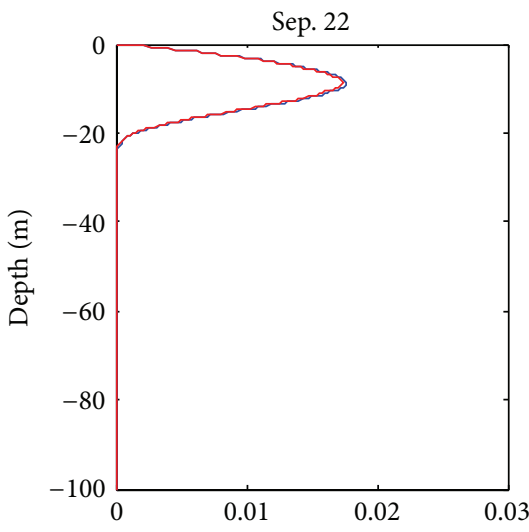

(a)

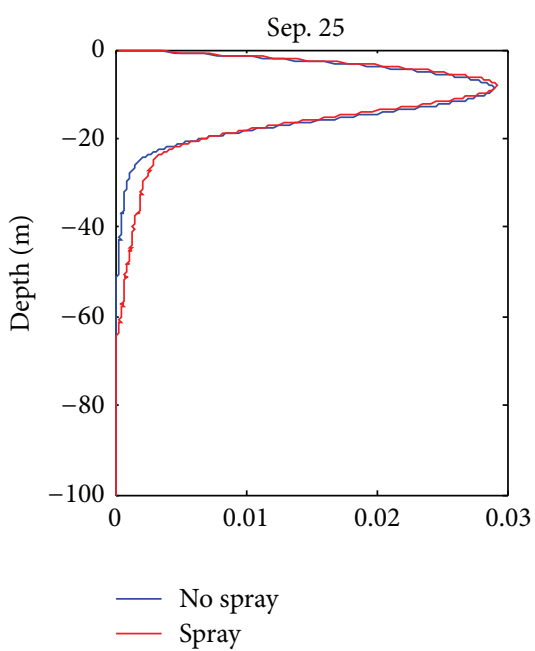

(d)

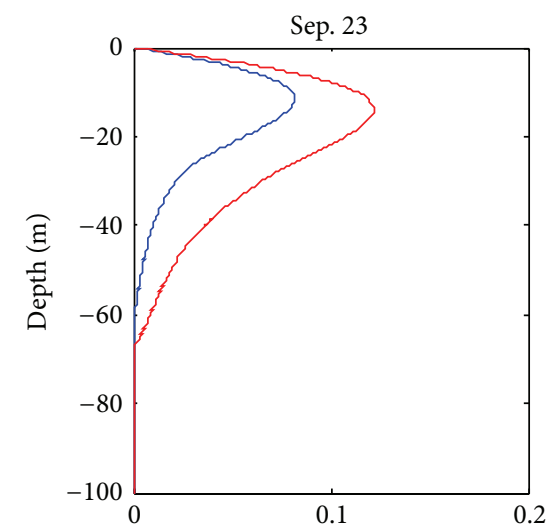

(b)

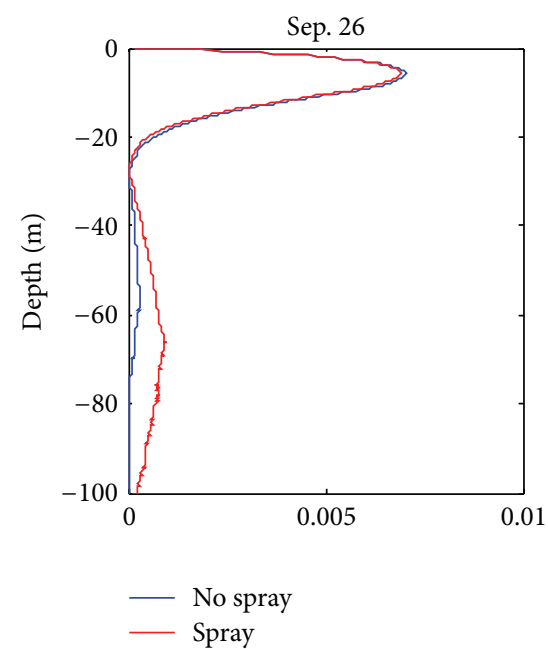

(e)

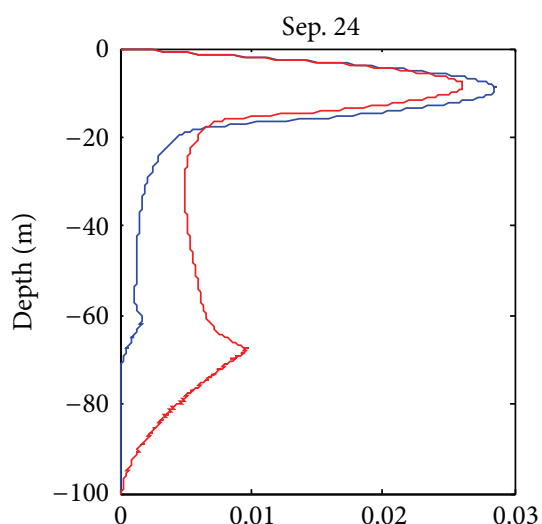

(c)

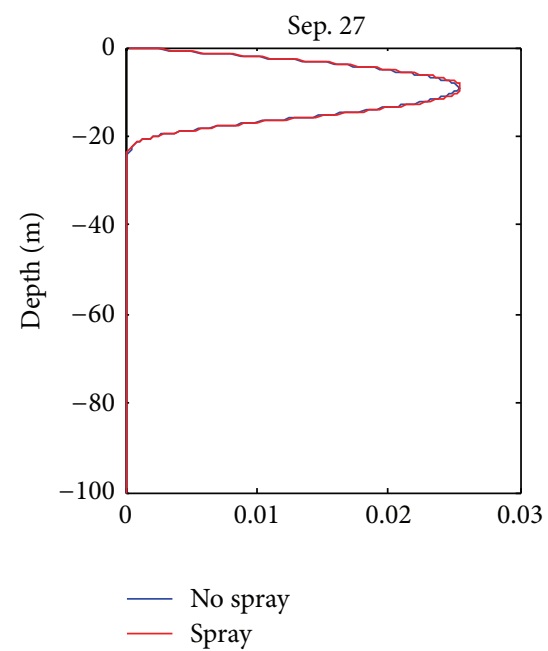

(f)

Figure 14: Upper $100 \mathrm{~m} \mathrm{~K}_{h}$ daily profiles simulated by Test 1 (no spray, blue curves) and Test 2 (spray, red curves) on September 22-27 ((a)-(f)), 2006.

coupled model should be used to understand the feedback process between sea spray and air-sea interface.

\section{Conflict of Interests}

The authors declare that there is no conflict of interests regarding the publication of this paper.

\section{Acknowledgments}

The authors would like to express their gratitude to two reviewers for their helpful comments and suggestions, which contributed to greatly improving the original paper. This work was supported by the National Basic Research Program of China (no. 2013CB430304), National High-Tech R\&D Program of China (no. 2013AA09A505), and National Natural Science Foundation of China (nos. 41206178, 41376015, 41376013, and 41306006).

\section{References}

[1] Z. Xuefeng, H. Guijun, W. Dongxiao, L. Wei, and H. Zhongjie, "Effect of surface wave breaking on the surface boundary layer of temperature in the Yellow Sea in summer," Ocean Modelling, vol. 38, no. 3-4, pp. 267-279, 2011.

[2] X. F. Zhang, G. J. Han, D. X. Wang, Z. Deng, and W. Li, "Summer surface layer thermal response to surface gravity waves in the Yellow Sea," Ocean Dynamics, vol. 62, no. 7, pp. 983-1000, 2012.

[3] L. X. Zhang, G. J. Han, W. Li et al., "The effects of sea spray on the air-sea turbulent fluxes during the typhoon passage," Acta Oceanologica Scinica, vol. 36, no. 11, pp. 46-56, 2014 (Chinese).

[4] L. X. Zhang, X. F. Zhang, G. J. Han et al., "Impact of sea spray on upper ocean temperature during typhoon passage: simulation with a 1-D turbulent model," Chinese Journal of Oceanology and Limnology, 2015.

[5] H. Riehl, Tropical Meteorology, McGraw-Hill, New York, NY, USA, 1954. 
[6] P. A. Mangarella, A. J. Chambers, R. L. Street, and E. Y. Hsu, "Laboratory studies of evaporation and energy transfer through a wavy air-water interface," Journal of Physical Oceanography, vol. 3, no. 1, pp. 93-101, 1973.

[7] R. J. Lai and E. J. Plate, "Evaporation form small wind waves," Tech. Rep. CER68-69JRL35, Department of Civil Engineering, Colorado State University, 1969.

[8] C. C. Easterbrook, "A study of spray and its contributions to total evaporation,” Tech. Rep. CAL RM-2865-P-L, Cornell Teah. Lab., Inc., Buffalo, NY, USA, 1970.

[9] R. S. Bortkovskii, "On the mechanism of interaction between the ocean and the atmosphere during a strom," Fluid MechanicsSoviet Research, vol. 2, no. 2, pp. 87-94, 1973.

[10] J. Wu, "Evaporation due to spray," Journal of Geophysical Research, vol. 79, no. 27, pp. 4107-4109, 1974.

[11] S. C. Ling and T. W. Kao, "Parameterization of the moisture and heat transfer process over the ocean under whitecap sea states," Journal of Physical Oceanography, vol. 11, pp. 324-336, 1976.

[12] R. A. Anthes, Tropical Cyclones: Their Evolution, Structure and Effects, vol. 41 of Meteorological Monographs, American Meteorological Society, 1982.

[13] H. Zhang and S. L. Lou, "Effects of spray on the momentum, heat and vapor transfers over the sea I. Equations and initial values," Journal of Ocean University of Qingdao, vol. 25, no. 2, pp. 131-138, 1995.

[14] S. L. Lou and H. Zhang, "Effects of spray on the momentum, heat and vapor transfers over the sea II. Numerical calculations and comparison of results," Journal of Ocean University of Qingdao, vol. 25, no. 2, pp. 139-145, 1995 (Chinese).

[15] L. Hasse, "On the contribution of spray droplets to evaporation," Boundary-Layer Meteorology, vol. 61, no. 3, pp. 309-313, 1992.

[16] M. P. Rouault, P. G. Mestayer, and R. Schiestel, "A model of evaporating spray droplet dispersion," Journal of Geophysical Research, vol. 96, no. 4, pp. 7181-7200, 1991.

[17] E. L. Andreas, "Thermal and size evolution of sea spray droplets," CRREL Report 89-11, U.S. Army Cold Regions Research and Engineering Laboratory, Hanover, NH, USA, 1989.

[18] E. L. Andreas, "Time constants for the evolution of sea spray droplets," Tellus, Series B, vol. 42, no. 5, pp. 481-497, 1990.

[19] E. L. Andreas, "Sea spray and the turbulent air-sea heat fluxes," Journal of Geophysical Research, vol. 97, pp. 11429-11441, 1992.

[20] H. R. Pruppacher and J. D. Klett, Microphysics of Clouds and Precipitation, D. Reidel, Norwell, Mass, USA, 1978.

[21] C. W. Fairall, J. D. Kepert, and G. J. Holland, "The effect of sea spray on surface energy transports over the ocean," The Global Atmosphere-Ocean System, vol. 2, pp. 121-142, 1994.

[22] K. A. Emanuel, "Sensitivity of tropical cyclones to surface exchange coefficients and revised steady-state model incorporating eye dynamics," Journal of the Atmospheric Sciences, vol. 52, no. 22, pp. 3969-3976, 1995.

[23] M. D. Powell, P. J. Vickery, and T. A. Reinhold, "Reduced drag coefficient for high wind speeds in tropical cyclones," Nature, vol. 422, no. 6929, pp. 279-283, 2003.

[24] E. Jarosz, D. A. Mitchell, D. W. Wang, and W. J. Teague, "Bottom-up determination of air-sea momentum exchange under a major tropical cyclone," Science, vol. 315, no. 5819, pp. 1707-1709, 2007.

[25] V. K. Makin, "A note on the drag of the sea surface at hurricane winds," Boundary-Layer Meteorology, vol. 115, no. 1, pp. 169-176, 2005.
[26] J.-W. Bao, J. M. Wilczak, J.-K. Choi, and L. H. Kantha, "Numerical simulations of air-sea interaction under high wind conditions using a coupled model: a study of Hurricane development," Monthly Weather Review, vol. 128, no. 7, pp. 2190-2210, 2000.

[27] J. F. Meirink and V. K. Makin, "The impact of sea spray evaporation in a numerical weather prediction model," Journal of the Atmospheric Sciences, vol. 58, no. 23, pp. 3626-3638, 2001.

[28] J. S. Gall, W. M. Frank, and Y. Kwon, "Effects of sea spray on tropical cyclones simulated under idealized conditions," Monthly Weather Review, vol. 136, no. 5, pp. 1686-1705, 2008.

[29] C. L. Uang, "Impact of sea spray and oceanic on the development of tropical cyclones," in Proceedings of the 23rd Conference on Hurricanes and Tropical Meteorology, pp. 30-31, American Meteorological Society, Dallas, Tex, USA, 1999.

[30] Y. M. Wang, J. D. Kepert, and G. J. Holland, “The effect of sea spray evaporation on tropical cyclone boundary layer structure and intensity," Monthly Weather Review, vol. 129, no. 10, pp. 2481-2500, 2001.

[31] H. Burchard, K. Bolding, W. Kühn, A. Meister, T. Neumann, and L. Umlauf, "Description of a flexible and extendable physicalbiogeochemical model system for the water column," Journal of Marine Systems, vol. 61, no. 3-4, pp. 180-211, 2006.

[32] L. Umlauf and H. Burchard, "Second-order turbulence closure models for geophysical boundary layers. A review of recent work," Continental Shelf Research, vol. 25, no. 7-8, pp. 795-827, 2005.

[33] C. W. Fairall, E. F. Bradley, D. P. Rogers, J. B. Edson, and G. S. Young, "Bulk parameterization of air-sea fluxes for tropical oceanglobal atmosphere coupled-ocean atmosphere response experiment," Journal of Geophysical Research C: Oceans, vol. 101, no. 2, pp. 3747-3764, 1996.

[34] B. Liu, C. Guan, and L. Xie, “The wave state and sea spray related parameterization of wind stress applicable from low to extreme winds," Journal of Geophysical Research C: Oceans, vol. 117, pp. 1-10, 2012.

[35] A. Masuda and T. Kusaba, "On the local equilibrium of winds and wind-waves in relation to surface drag," Journal of the Oceanographical Society of Japan, vol. 43, no. 1, pp. 28-36, 1987.

[36] N. Maat, C. Kraan, and W. A. Oost, "The roughness of wind waves," Boundary-Layer Meteorology, vol. 54, no. 1-2, pp. 89-103, 1991.

[37] J. Monbaliu, "On the use of the Donelan wave spectral parameter as a measure for the roughness of wind waves," BoundaryLayer Meteorology, vol. 67, no. 3, pp. 277-291, 1994.

[38] D. Vickers and L. Mahrt, "Fetch limited drag coefficients," Boundary-Layer Meteorology, vol. 85, no. 1, pp. 53-79, 1997.

[39] H. K. Johnson, J. Højstrup, H. J. Vested, and S. E. Larsen, "On the dependence of sea surface roughness on wind waves," Journal of Physical Oceanography, vol. 28, no. 9, pp. 1702-1716, 1998.

[40] M. A. Donelan, "Air-sea interaction," in The Sea, B. LeMehaute and D. M. Hanes, Eds., pp. 239-292, Wiley Interscience, New York, NY, USA, 1990.

[41] M. A. Donelan, F. W. Dobson, S. D. Smith, and R. J. Anderson, "On the dependence of sea surface roughness on wave development," Journal of Physical Oceanography, vol. 23, no. 9, pp. 2143-2149, 1993.

[42] Y. Toba, "Local balance in the air-sea boundary processes. I. On the growth process of wind waves," Journal of the Oceanographical Society of Japan, vol. 28, no. 3, pp. 109-120, 1972. 
[43] E. C. Monahan and I. O. Muircheartaigh, "Optimal power-law description of oceanic whitecap coverage dependence on wind speed," Journal of Physical Oceanography, vol. 10, no. 12, pp. 2094-2099, 1980.

[44] J. B. Edson, Lagrangian model simulation of the turbulent transport of evaporating jet droplets [Ph.D. thesis], Pennsylvania State University, State College, Pa, USA, 1989.

[45] M. A. Miller and C. W. Fairall, "A new parameterisation of aerosol generation in the marine planetary boundary layer," in Proceedings of the 7th Conference on Ocean-Atmosphere Interaction, American Meteorological Society, Anaheim, Calif, USA, January 1988.

[46] D. K. Woolf, P. A. Bowyer, and E. C. Monahan, "Discriminating between the film drops and jet drops produced by a simulated whitecap," Journal of Geophysical Research: Oceans, vol. 92, no. C5, pp. 5142-5150, 1987.

[47] G. de Leeuw, "Vertical profiles of giant particles close above the sea surface," Tellus, vol. 38, no. 1, pp. 51-61, 1986.

[48] G. de Leeuw, "Near-surface particle size distribution profiles over the North Sea," Journal of Geophysical Research, vol. 92, no. 13, pp. 14631-14635, 1987.

[49] G. de Leeuw, "Profiling of aerosol concentrations, particle size distributions and relative humidity in the atmospheric surface layer over the North Sea," Tellus, vol. 42B, no. 4, pp. 342-354, 1990.

[50] J. B. Edson, "Simulating droplet motion above a moving surface," in Modeling the Fate and Influence of Marine Spray, P. Mestayer, E. C. Monahan, and P. A. Beetham, Eds., Whitecap Report 7, pp. 84-94, University of Connecticut, Marine Sciences Institute, Groton, Conn, USA, 1990.

[51] M. P. Rouault and S. E. Larsen, "Spray droplet under turbulent conditions," Tech. Rep. RISO-M-2845, Department of Meteorology and Wind Energy, Risø National Laboratory, Roskilde, Denmark, 1990.

[52] E. L. Andreas and J. DeCosmo, "Sea spray production and influence on air-sea heat and moisture fluxes over the open ocean," in Air-Sea Exchange: Physics, Chemistry and Dynamics, G. L. Geernaert, Ed., pp. 327-362, Kluwer Academic, 1999.

[53] E. L. Andreas, "An algorithm to predict the turbulent air-sea fluxes in high-wind," in Proceedings of the 12th Conference on Interactions of the Sea and Atmosphere, Amer Meteor Soc, Long Beach, Calif, USA, 2003, CD-ROM 3.4:7.

[54] Z. H. Liu, J. P. Xu, B. K. Zhu, C. H. Sun, and L. F. Zhang, "Upper ocean to tropical cyclones in northwestern Pacific during 20012004 by Argo data," Journal of Tropical Oceanography, vol. 25, pp. 1-8, 2006 (Chinese).

[55] E. L. Andreas and K. A. Emanuel, "Effects of sea spray on tropical cyclone intensity," Journal of the Atmospheric Sciences, vol. 58, no. 24, pp. 3741-3751, 2001. 

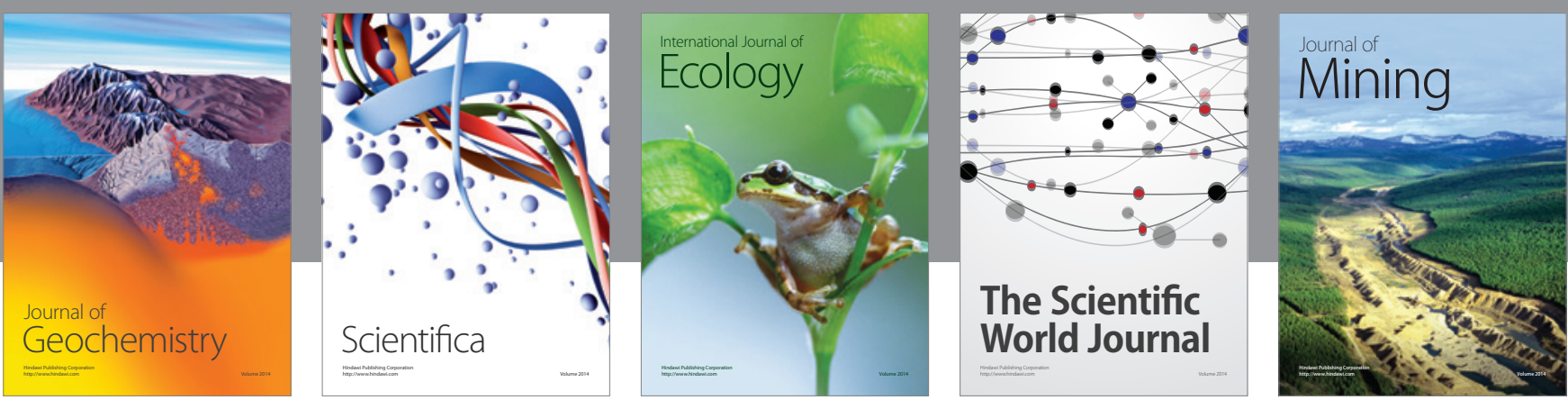

The Scientific World Journal
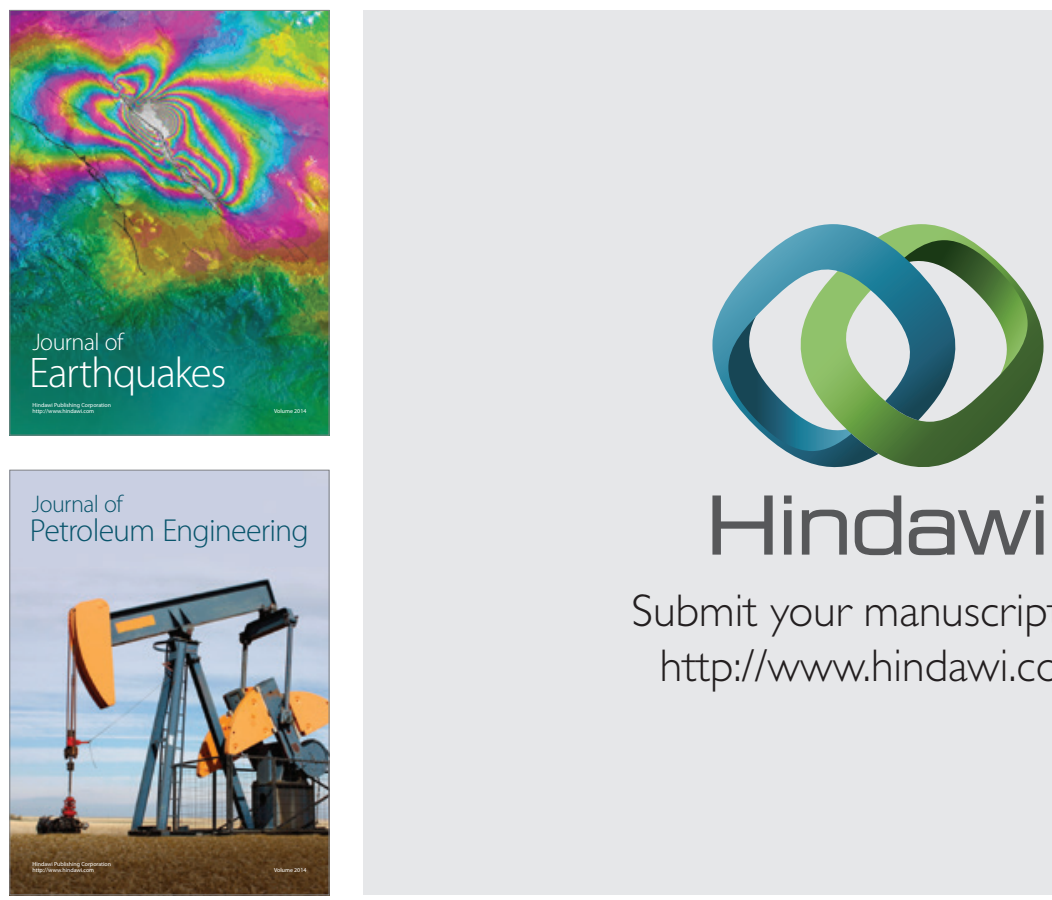

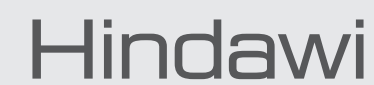

Submit your manuscripts at

http://www.hindawi.com
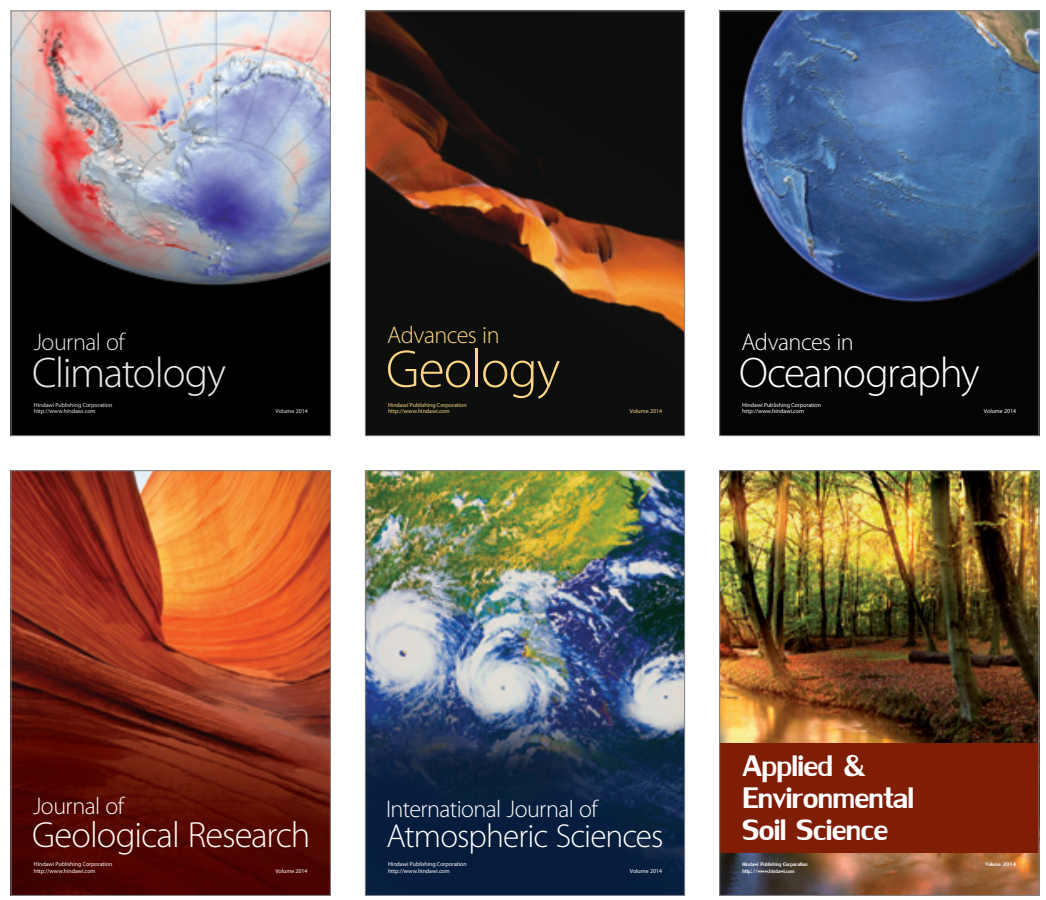
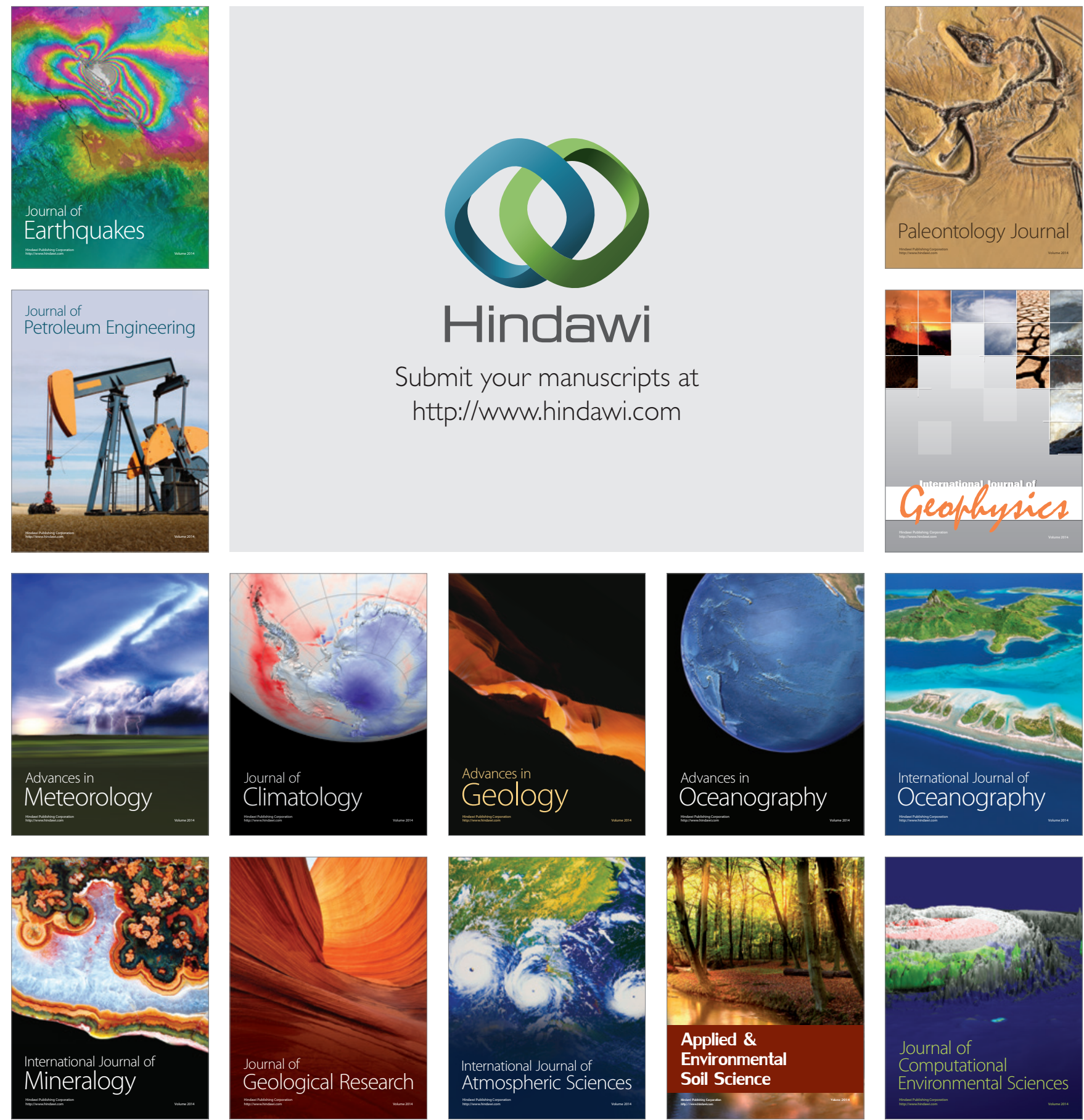